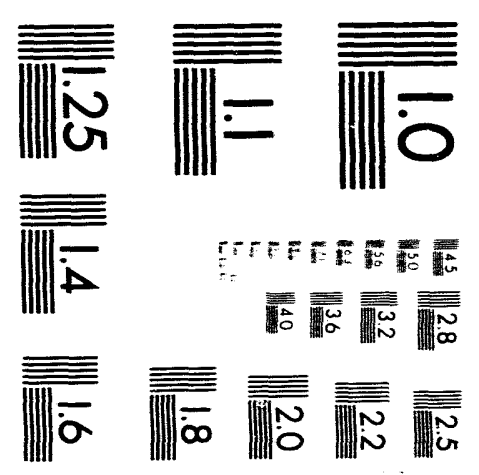



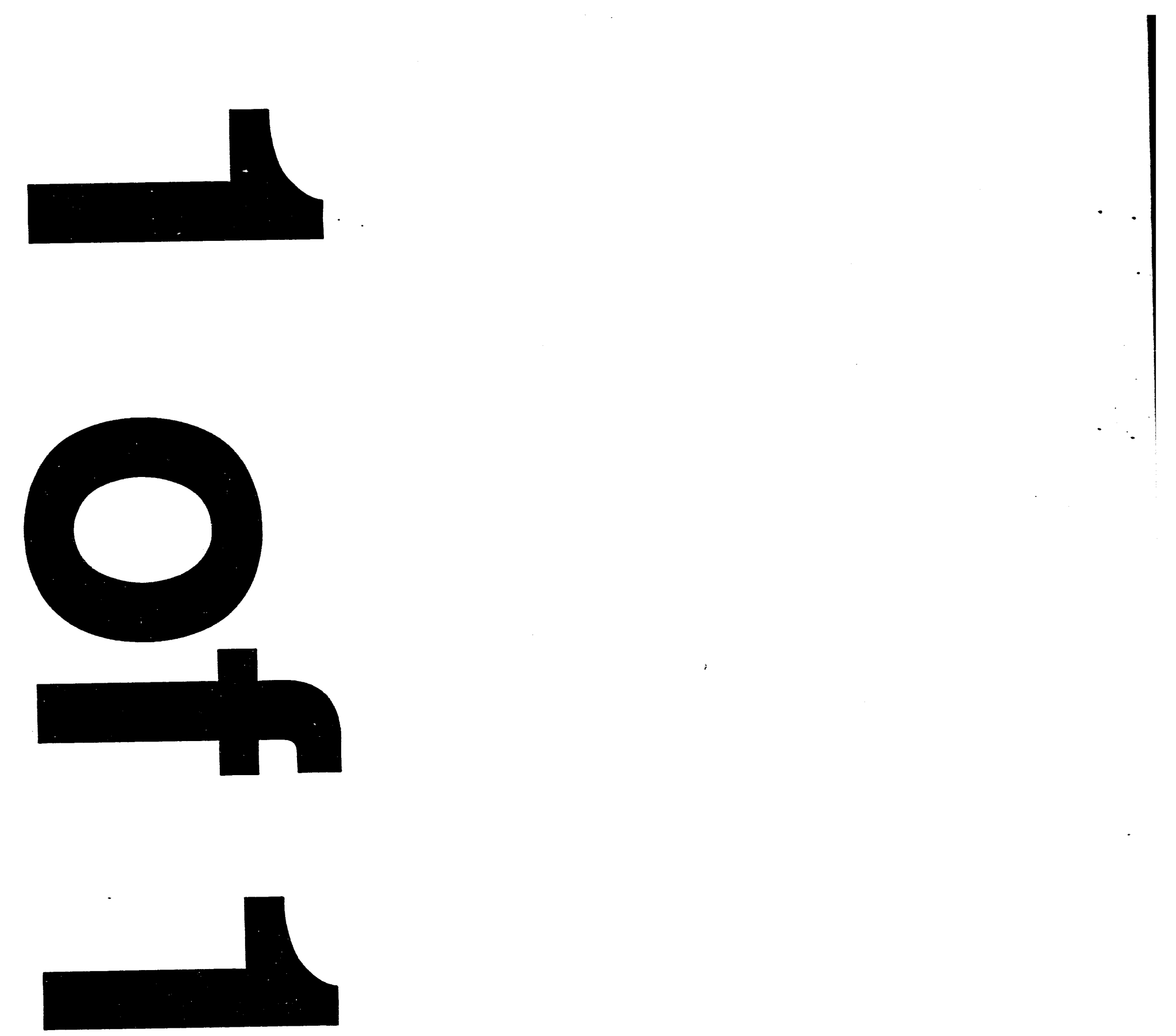


\title{
Test Plan for Dig-Face Characterization Performance Testing
}

\author{
N.E. Josten
}

Published September 1993

\author{
Idaho National Engineering Laboratory \\ EG\&G Idaho, Inc. \\ Idaho Falls, Idaho 83415
}

Prepared the

U.S. Department of Energy

Office of Environmental Restoration and Waste Management

Under DOE Idaho Operations Office

Contract DE-AC07-76ID01570 


\title{
Test Plan for Dig-Face Characterization Performance Testing
}

\author{
EGG-WTD-10766
}

Prepared by

A.S. Qmoth

N. E. Josten/Senior Scientist Applied Geosciences

Reviewed by

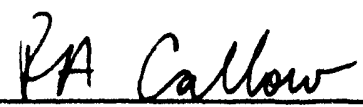

R. A. Callow, Project Manager

Buried Waste Integrated Demonstration

Approved by

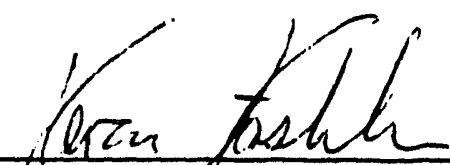

K. M. Kostelnik, Coordinator

Buried Waste Integrated Demonstration

\section{$8 / 27 / 93$ Date}

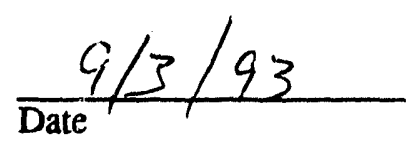




\begin{abstract}
The dig-face characterization concept has been under development at the Idaho National Engineering Laboratory (INEL) since FY 1992 through the support of the Buried Waste Integrated Demonstration Program. A Dig-face Characterization System conducts continuous subsurface characterization simultaneously with retrieval of hazardous and radioactive waste from buried waste sites. The system deploys multiple sensors at the retrieval operation dig-face and collects data that provide a basis for detecting, locating, and identifying hazardous conditions before they are disturbed by the retrieval equipment. This test plan describes initial efforts to test the dig-face characterization concept at the INEL Cold Test Pit using a simplified prototype apparatus and off-the-shelf sensors. The Cold Test Pit is a simulated waste site containing hazardous and radioactive waste surrogates at known locations. Testing will be directed toward three generic characterization problems: metal detection, plume detection, and radioactive source detection. The prototype apparatus will gather data using magnetometers, a ground conductivity meter, a trace gas analyzer, and a gamma ray sensor during simulated retrieval of the surrogate waste materials. The data acquired by a dig-face characterization system are unique because of the high precision, high data density, and multiple viewpoints attainable through the dig-face deployment approach. The test plan establishes procedures for collecting and validating a representative dig-face characterization data set. Analysis of these data will focus on developing criteria for predicting the depth, location, composition, and other characteristics of the surrogate waste materials. If successful, this proof-of-concept exercise will provide a foundation for future development of a fully-operational system that is capable of operating on an actual waste site.
\end{abstract}




\section{CONTENTS}

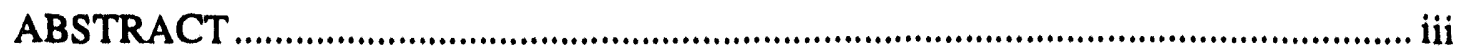

ACRONYMS …......................................................................................... vii

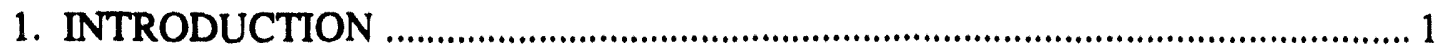

1.1 Technology Description and Background.................................................... 3

1.2 Scope of Test..............................................................................................

1.3 BWID Program Cbjectives .................................................................... 8

1.4 Dig-Face Characierization Test Objectives ............................................... 8

1.4.1 Metal Detection .................................................................................. 9

1.4.2 Plume Detection ........................................................................... 10

1.4.3 Radiation Source Detection ......................................................... 11

1.5 Technology Agreement ................................................................................. 12

2. ORGANIZATION AND RESPONSIBILITIES …............................................ 13

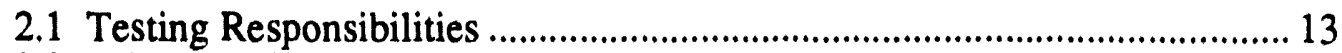

2.2 Additional Required Support …………..................................................... 13

2.3 Personnel Qualifications and Training........................................................ 15

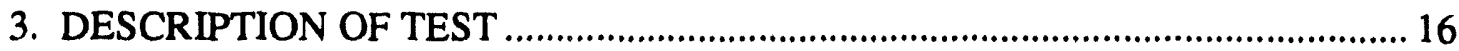

3.1 Test Strategy ............................................................................................ 16

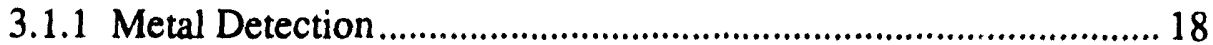

3.1.2 Plume Detection .......................................................................... 19

3.1.3 Radiation Source Detection .......................................................... 19

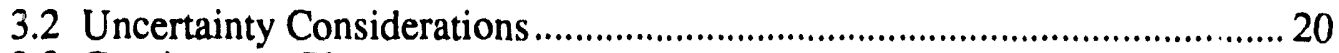

3.3 Contingency Plans ...................................................................................... 21

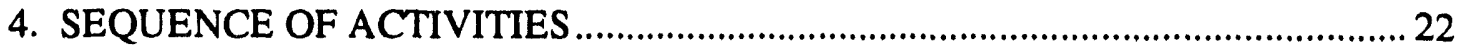

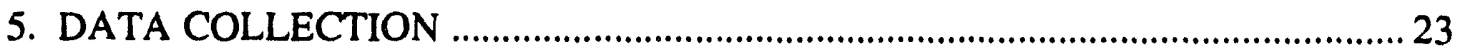

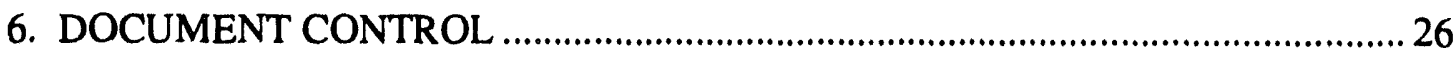

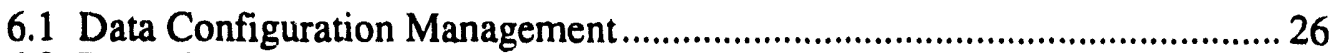

6.2 Test Plan .............................................................................................. 26

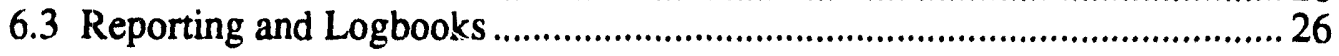

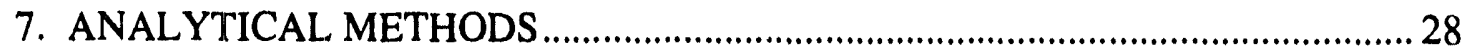

8. DATA REDUCTION, VALIDATION, AND VERIFICATION ................................ 29

8.1 Data Validation and Verification ............................................................. 29 
9. QUALITY ASSURANCE

9.1 General Quality Control Methods ..............................................................32

9.2 Specific Quality Control Procedures........................................................... 32

10. EQUIPMENT AND INSTRUMENTS ........................................................... 34

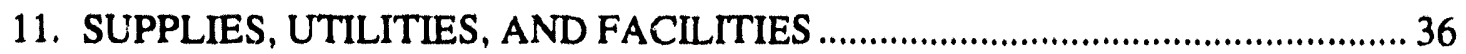

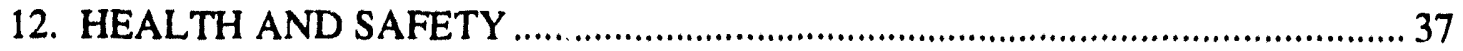

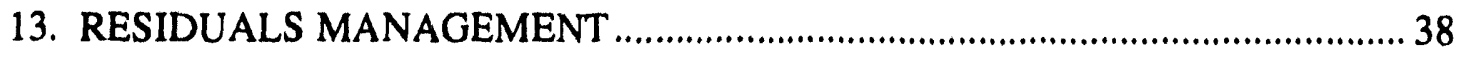

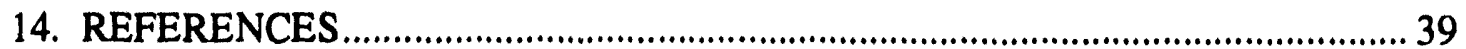

Appendix A-Sensor Technical Specifications..............................................................

Appendix B-Procedures for Handling and Use of Cs-137 Source at the Cold Test Pit.................................................................................... B-1

Appendix C -Detailed Test Procedures ...................................................................... C-1

C-1. Basic Experimental Procedure ….................................................................. C-1

C-2. Detailed Procedure for Surveying a Test Area …………………….......... C-2

Appendix D-Proposed Specifications for Additional Test Cells................................... D1

\section{FIGURES}

1 Schematic drawing of a Safe Step Remediation System showing the relationship between Dig-face Characterization and the other major activities involved in retrieval of a complex and dangerous buried waste site. 2

2.. $\quad$ Schematic drawing showing the three major components of a Dig-Face Characterization System. Each of these components is represented within the prototype system being used for the FY-93 performance testing 5

3. Perspective, side view and plan view drawings of the manual trolley structure that will be used for the FY93 performance tests. The trolley is constructed almost exclusively from fiberglass and plastic parts to avoid interference effects when deploying metal detecting sensors.

4. Summary of key project personnel for the Dig-face Characterization Project trench experiments.

5. Diagram showing the Characterization Cell at the INEL Cold Test Pit. (Based on drawings from Winberg 1992).

6. Schematic drawing showing setup of the trolley over a test cell. Drawing shows the approximate working range of the trolley in feet. 
7. Illustration of the sequence of trolley motions required to collect three dimensional dig-face characterization data. Note definitions of the data acquisition parameters $\Delta x, \Delta y$, and $\Delta z$.

\section{TABLES}

1. Operating parameters and conversion factors for dig-face characterization sensors.....31

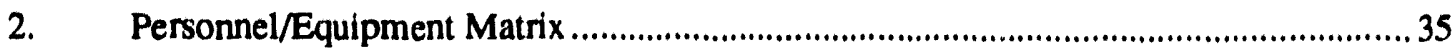




\section{ACRONYMS}

BWID

DOE

EMDS

FY

$\mathrm{HNu}$

INEL

PC

QC

RWMC

TRA

TTP
Buried Waste Integrated Demonstration

U. S. Department of Energy

Electro Mechanical Design Services, Inc.

fiscal year

photoionization detector

Idaho National Engineering Laboratory

personal computer

quality control

Radioactive Waste Management Complex

Test Reactor Area

Technical Task Plan 


\section{TEST PLAN FOR DIG-FACE CHARACTERIZATION PERFORMANCE TESTING}

\section{INTRODUCTION}

Large, unremediated mixed-waste burial sites throughout the U. S. Department of Energy (DOE) system are symptoms of the inadequacy of conventional buried waste characterization schemes. Conventional characterization efforts fall short of providing the level of information concerning hazardous waste that is consistent with human safety during waste retrieval operations. As a result, progress on cleanup of DOE waste sites has been slow. This test plan describes initial efforts to evaluate a new approach to hazardous waste cleanup. The key component of this approach is a characterization technology that works at the dig-face of a retrieval operation. This technology, herein called a Dig-face Characterization System, produces characterization data in small, precise increments. The first increment merely makes the decision to begin the retrieval operation tenable. Each new increment provides the impetus to press on.

Unknown hazards must be assumed to exist at all stages of a retrieval operation, no matter what level of study has been performed. Dig-face characterization technology searches for these hazards continuously by scanning the dig-face of the retrieval operation with an array of focused sensors. Earth moving and retrieval operations may proceed steadily in safe steps, while the sensors monitor and characterize approaching hazards. A waming is issued when it is no longer safe to proceed. The hazard is now in a position where it can be thoroughly and confidently, but still safely evaluated. The correct information is gathered for choosing a retrieval technology that is efficient and effective. Meanwhile, routine operations continue away from the hazard. The linkage of a retrieval operation with simultaneous characterization at the dig-face defines the concept of a Sufe Step Remediation System (Figure 1).

No characterization technology has ever been developed that (a) permits remediation to progress safely in the presence of unknown hazards, (b) provides the timely information needed to adapt remediation to handle changing hazardous conditions, and (c) is deployed continuously and simultaneously with the remediation technology at the dig-face. Dig-Face Characterization is a clear, serious effort to address the DOE Bias for Action as well as the restrictive environmental and safety requirements that govem retrieval. A Dig-face Characterization System will ultimately:

- Enable retrieval to begin on complex, poorly understood sites by providing a means to manage risks 


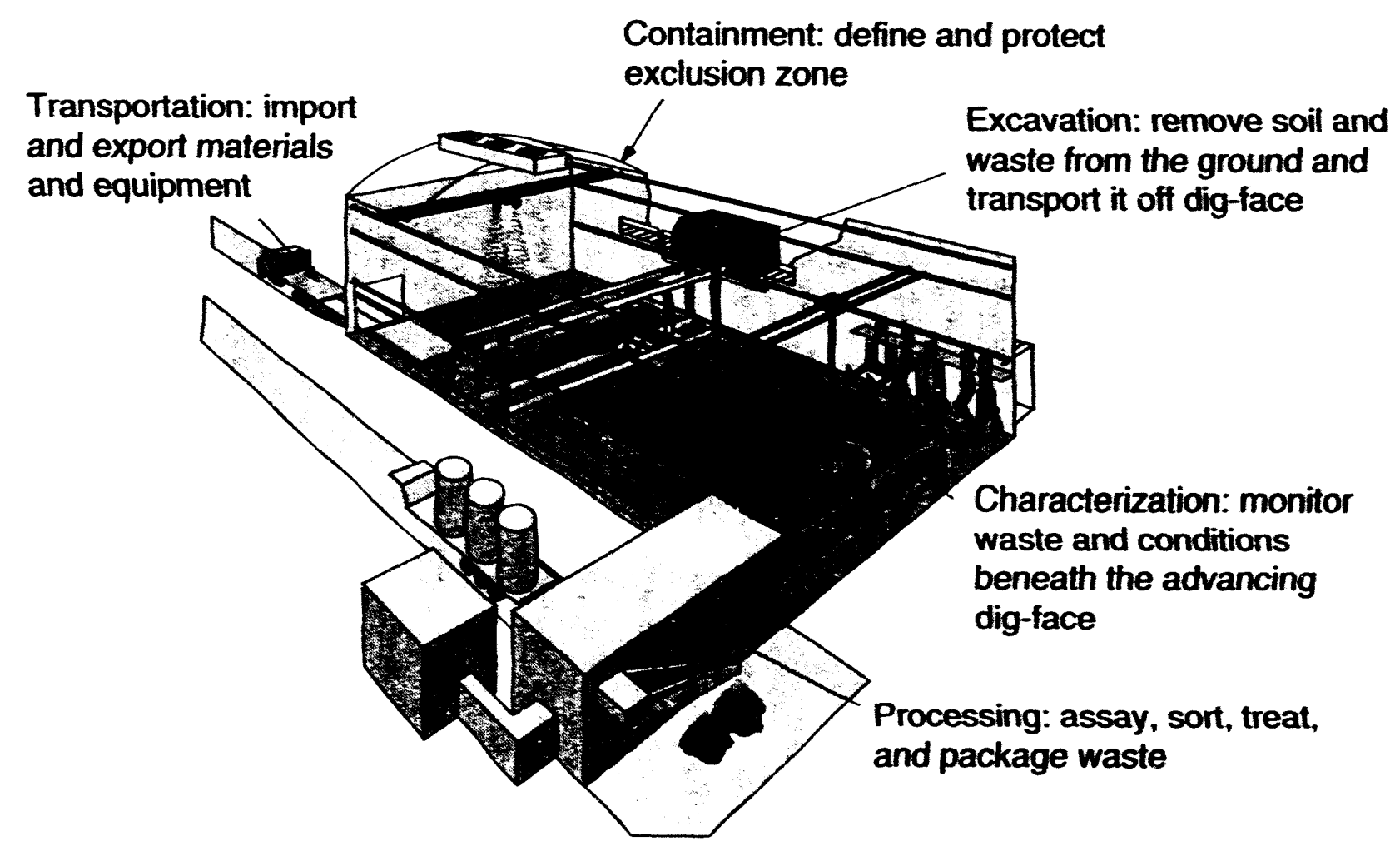

Figure 1. Schematic drawing of a Safe Step Remediation System showing the relationship between Digface Characterization and the other major activities involved in retrieval of a complex and dangerous buried waste site. 
- Reduce the overall environmental. health and safety risks during retrleval

- Improve the efficiency of retrieval by directing expensive waste retrieval efforts only to areas that are hazardous

- Have wide application at DOE buried waste sites.

The FY-93 Dig-face Characterization Project involves two distinct activities. The first activity involves a set of performance tests focused on the central issue of characterization sensors, sensor data, and the interpretation of these data to identify hazardous conditions. These tests will be conducted at an outduor, full-scale experimental waste trench and will directly assess baseline capabilities for detecting and identifying subsurface conditions that are of interest during a remedial operation. This activity is the subject of the present test plan. The second FY.93 project activity addresses dig-face characterization at a more general systems level. This activity focuses on technology evaluation relevant to robotic operations of Dig-Face Characterization and is covered in a separate test plan (Croft et al. 1993).

The Dig-Face Characterization Project has been funded and managed by the Buried Waste Integrated Demonstration Program (BWID) at the Idaho National Engineering Laboratory (INEL) beginning with a conceptual design effort in FY.92 (Josten 1992). BWID has supported dig-face characterization as one of the broad suite of technologies necessary to remediate large, complex DOE mixed waste landfills.

\subsection{Technology Description and Barikground}

Dig-face Characterization addresses the fundamental need to conduct online monitoring during waste retrieval efforts, a need that arises from both safety and efficiency considerations during cleanup of a complex waste site. Waste retrieval involves initial, uncontrolled contact with unknown and potentially dangerous materials and, thus, constitutes one of the biggest safety risks during a remedial process. Waste retrieval also initiates the complex chain of events that leads to assaying, sorting, treating and disposing waste materials - activities that strongly influence the speed, cost, and effectiveness of the remediation process. Information conceming conditions at the active dig-face can be used by operators as a basis for adjusting retrieval activities to reduce safety risks and to promote a smooth transition from retrieval to follow-on activities.

Three technologies combine to create a Dig-face Characterization System. The sensor subsystem consists of the set of sensors for interrogating the waste seam. The need to detect and classify a broad assortment of hazard types demands a multisensor approach that simultaneously addresses the chemical, 
radiological, and physical conditions in the subsurface. The scanning subsystem delivers the senson to desired measurement points on and above the active dig-face. The data analysis subsystem initiates measurements, validates and stores the sensor data, and provides an operator with rapid. Uloughtful access to the sensor data to facilitate data interpretation. Figure 2 gives a schematic illustration of the Dig. face Characterization Subsystems.

The performance testing described in this test plan focuses on establishing the feasibility of dig.face characterization. The prototype system that has been assembled for these tests is by no means a comprehensive hazard monitoring system. Instead. it has been designed to facilitate evaluation of the overall dig-face characterization concept through investigation of the unique and presumed beneficial data enhancements provided by the dig-face deployment approach. It is believed that proof-of-concept can be established through evaluation of data collected by a limited sensor suite. The capabilities of a future. more complete sensor suite may be assessed based on these preliminary results.

The FY.93 tests will utilize four commercially avallable sensor types: magnetometers, an electromagnetic conductivity meter, a photo lonization-based trace gas analyzer, and a passive gamma my sensor. Appendix A provides a detalled description of these sensors. The sensors will be deployed over a simulated dig-face using a manually operated, non-interfering trolley. A personal computer based data acquisition system will function to initiate sensor measurements and store incoming data. Data analysis will be performed in a postprocessing mode. Analysis will focus on developing an interpretive basis for making dig or no-dig decisions, which can form the foundation for future real-time analysis capabilities.

A noninterfering, manual three-axis trolley has been fabricated at the INEL exclusively for dig-face performance testing. The major structural elements of the manual trolley are fiberglass, and the amount of ferrous and conducting materials are minimized to avoid interference with metal detection sensors. The system is designed to provide sensor positioning accuracy of approximately \pm 1 inch throughout the volume accessible by the trolley.

Figure 3 shows an engineering drawing of the trolley structure. The trolley $x$-axis provides approximately $15 \mathrm{ft}$ of linear travel distance aligned parallel to the simulated trench. The $y$-axis provides capabilities to span a trench up to $15 \mathrm{ft}$ wide. The 2 -axis provides $7 \mathrm{ft}$ of vertical motion ( $2 \mathrm{ft}$ above and 5 $\mathrm{ft}$ below the base of the trolley). Radial encoders incorporated into the trolley axes will output trolley position on a real-time basis. The trolley is designed for fully manual operation, although small motors can be easily incorporated to drive the major axes motions. 
Data Analysis subsystem: anahysis of

sensor data to determine dig-face conditions;

incorporates data acquisition, data storage,

and data display functions.
Scanning subsystem: positions sensors

for making measurements; must have capabitity

to precisely position sensor an, where on or

above dig-face.
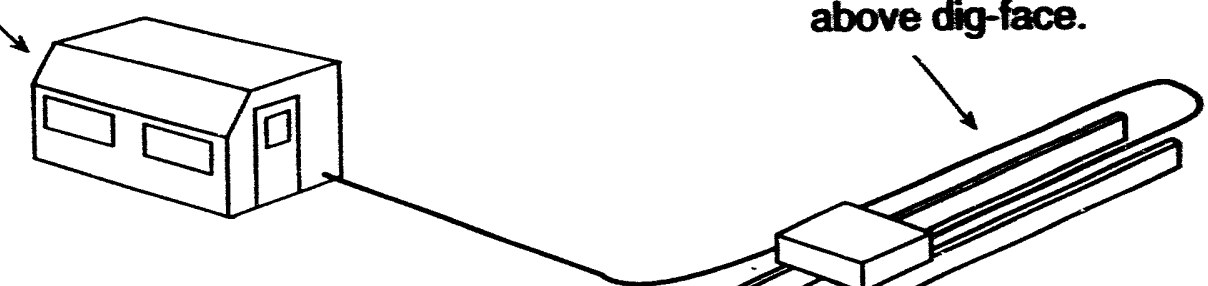

Depth of investigation

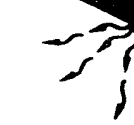

Error margin

Sensor subsystem: monitors chemical, radiological, and physical conditions

in the subsurface; multiple sensors are interchangeable and selectable.

Figure 2. Schematic drawing showing the three major components of a Dig-Face Characterization System. Each of these components is represented within the prototype system being used for the FY-93 performance testing. 


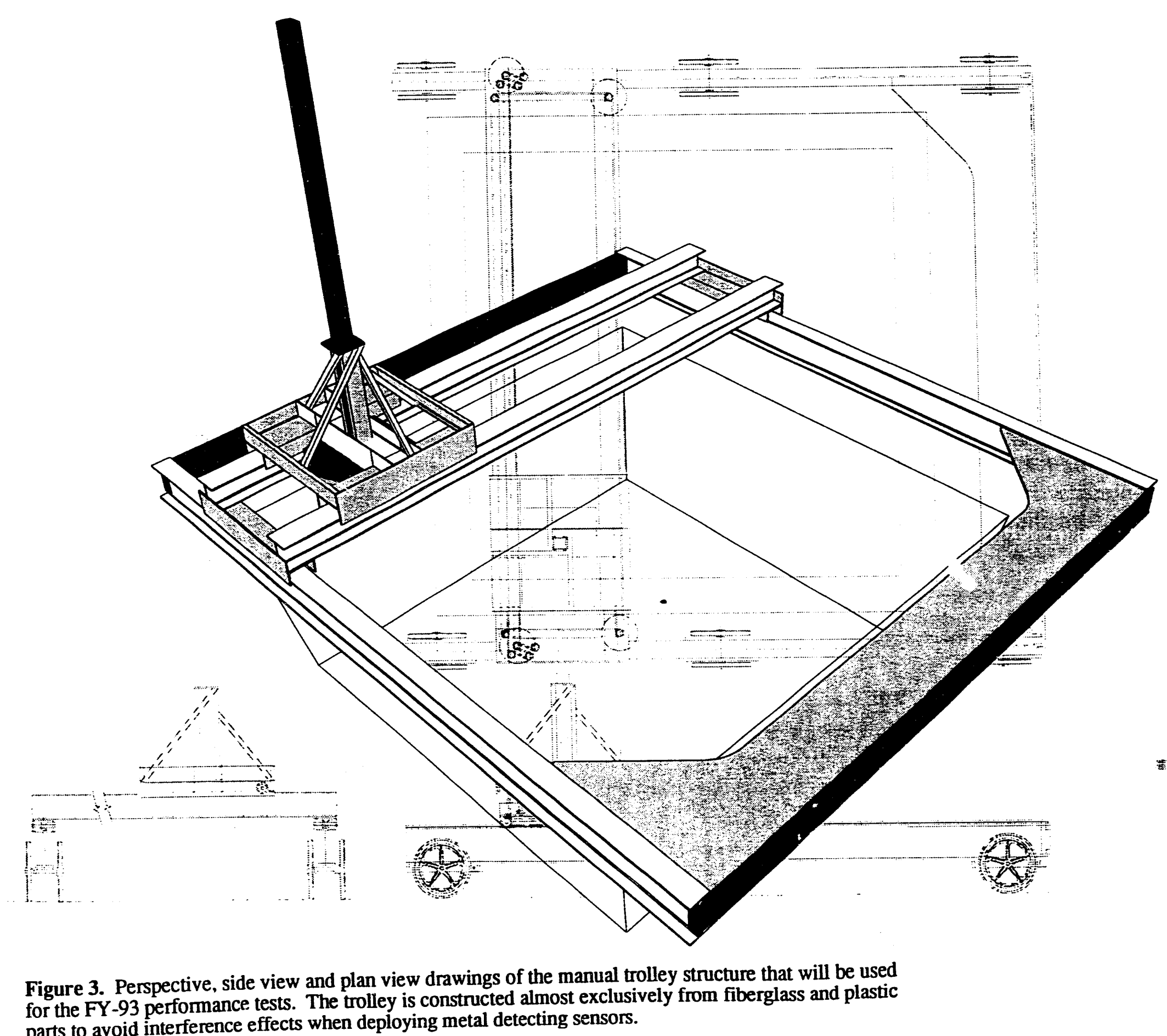


The data acquisition system monitors output from the trolley's radial encoders and triggers the characterization sensors to make measurements at prescribed spatial intervals. The acquisition system digitizes incoming analog signals from the sensors, provides display of the data for quality control purposes, and stores the data in mass storage.

Data analysis will be performed using commercially available software. The software will include data base, mapping, graphics, and spreadsheet packages, as well as a high-level programming language to allow complete flexibility in developing an approach for analyzing large, multisensor data sets. Analysis will be pursued beginning with careful observation and comparison of sensor data in relation to the known locations of buried objects. The goal is to identify critical indicators of object depth, position, composition, and other important parameters as described in Section 1.4.

\subsection{Scope of Test}

Dig-Face Characterization is focused on detecting and identifying hazardous materials beneath an advancing dig-face so that retrieval may be managed safely and efficiently. The test scope described in this test plan covers evaluation of capabilities for achieving this final product of dig-face characterization --hazard assessment--on a limited set of simulated hazards. The sensors, trolley, and data acquisition system being assembled for these tests constitute a prototype version of the dig-face characterization technology that includes the core sensing, scanning and analysis capabilities fundamental to a working system. The planned testing is intended to simulate actual dig-face conditions to the extent necessary to show that hazardous conditions can be detected and identified at a real hazardous site. The scope of this work specifically excludes any efforts to incorporate robotic operations or real-time analysis. This scope is covered in other test plans or will be addressed in future work.

The tests will utilize a preexisting full-scale, simulated waste pit containing surrogate waste materials at known locations. The prototype Dig-Face Characterization System will be set up over the pit to perform scanning of the subsurface as the surrogate waste is excavated and retrieved. This deployment mode will generate a very unique, high fidelity data set that permits an analyst to examine sensor responses in three dimensions and at various distances from buried targets. The goal is to identify the point at which the data become clearly indicative of specific targets of interest. Success in this effort will be measured by the ability to show this recognition point with specific reference to sensor or multisensor data patterns. 


\subsection{BWID Program Objectives}

BWID has identified conditions that could potentially delay or halt a retrieval program at a buried waste site (Mayberry et al. 1992; Morrison 1993). These conditions correspond to specific hazards or other circumstances that may exist at waste sites similar to Pit 9 at the INEL, and which could threaten the safety or efficiency of a waste retrieval operation. These conditions have been incorporated into a set of B WID core requirements as documented in Richardson et al. (1992).

- Conditions that contribute to a criticality hazard.

- Presence of atypical wastes, such as large or heavy objects and strong radiation sources, that require special handling or equipment.

- Presence of airbome or surface chemical contamination or radiation fields that raise concerns for maintenance workers or other personnel wearing bubble suits who must enter the work area during overburden removal or waste retrieval.

- Presence of hazardous materials in the retrieved waste stream that raise concerns for workers receiving these materials for processing.

- Regions of hazardous or radioactive contamination within the pit or trench overburden, where soils are presumed clean and more rapid retrieval techniques are employed.

- Point of transition between overburden and the waste seam.

Althnugh not specifically included in the design documents, the presence of conditions that promote explosions may constitute an additional concem.

\subsection{Dig-Face Characterization Test Objectives}

The performance testing described in this test plan is designed to evaluate capabilities for detecting and identifying a subset of the above listed conditions, as a means to establish proof-of-concept for digface characterization. The full characterization capability will be developed through outyear activities based on the results obtained from the FY-93 effort. The FY-93 project has been intentionally restricted to the use of off-the-shelf sensors so that resources and effort could be focused on the main issues of data collection and interpretation. The tests described in this test plan relate to hazardous conditions that can 
be addressed with metal detectors, a volatile gas detector, and a gamma radiation sensor. The critical aspect of the work is to determine the existence and nature of data patterns or indicators that provide a clear warning of these conditions. Procedures for finding these indicators will form the basis for complete development of dig-face characterization capabilities in the future. The intended approach to data analysis has been previously developed and is described by Graebner and Harthill (1992)

This dig-face characterization performance testing will involve deploying magnetometers, an electromagnetic conductivity meter, a photoionization-based trace gas analyzer, and a passive gamma sensor over the Characterization Cell of the INEL Cold Test Pit using the manual overhead trolley. The specific objectives are listed below.

\subsubsection{Metal Detection}

Metal containers are almost universally present in DOE waste sites, usually serving as primary containment for chemical or radioactive waste. The presence of containers, if known, serves as a useful indicator of possible contamination. Identification of containers by a dig-face characterization system allows the retrieval operation to be adjusted to avoid breaching contained waste, or to prepare for encountering free contamination around already breached containers.

Large metal objects, such as machines or structural steel, require special equipment for handling and moving. Early detection of such objects by a dig-face characterization system provides retrieval operators with the information needed to prepare special equipment or to modify the retrieval strategy to work efficiently around problem areas.

Metal detectors are extremely sensitive and can detect objects through significant overburden thicknesses. During overburden removal, the Dig-Face Characterization System will rely on metal detection to provide remedial operators with an early warning of buried waste and with reliable predictions of depth to the top of the waste.

The Characterization Cell contains various types of metal containers that will serve as targets for the metal detection experiments. If time permits, additional objects (including massive objects) will be buried for additional testing. In the prototype system, magnetometers will be used to detect ferrous metals, and an electromagnetic conductivity meter will be used to detect all types of conductive metals.

The specific objectives of the metal detection exercises are: 
- Develop a methodology for making magnetic measurements and induced electromagnetic field measurements for the purposes of detecting and characterizing metallic waste in the dig-face environment.

- Develop a methodology for interpreting these data in concert to determine the following five characteristics of metal waste: depth, location, size, shape (expecially containers), and type of metal (ferrous, nonferrous).

Develop a basis for evaluating the uncertainty in the above parameters as determined from magnetic and electromagnetic data. Determine the parameters that influence this uncertainty (e.g. overburden depth, interference from adjacent objects, data noise).

\subsubsection{Plume Detection}

Liquid contamination occurs in the subsurface of waste sites through two primary mechanisms: direct leakage of fluid filled storage containers and leachate generated by groundwater percolating through solid waste. Detection of fluid contaminant plumes by a dig-face chara terization system serves to warn remedial operators of possible dangers to workers entering a site and allows operations to be adjusted to avoid spreading free contaminants.

A volatile, nonhazardous organic fluid (isopropyl alcohol) and a nonvolatile conductive fluid (dilute salt solution) will be introduced into the Characterization Cell subsurface to evaluate plume detection capabilities. If time permits, a more complicated scenario involving plumes surrounding a metal container will be evaluated. In the prototype system, a photo-ionization based trace gas analyzer will be used to detect the volatile plumes, and an electromagnetic conductivity meter will be used to detect conductive/resistive plumes.

The specific objectives of the plume detection exercises are:

- Develop a methodology for making electromagnetic conductivity measurements and photo-ionization gas sensor measurements for the purpose of detecting identifying subsurface contaminant plumes. 
- Develop a methodology for interpreting these data in concert to determine the following three characteristics of a fluid plume:

1. Location of source (or highest concentration)

\section{Depth to source (or highest concentration)}

\section{Boundaries of contamination.}

- Develop a basis for evaluating the uncertainty in the above parameters as determined from conductivity measurements and photo-ionization data. Determine the parameters that influence this uncertainty.

\subsubsection{Radiation Source Detection}

Radioactive contamination occurs throughout many DOE mired waste landfills such as the Subsurface Disposal Area at the INEL. A dig-face characterization system can produce information regarding the strength and location of radioactive sources, warning remedial operators when a site may be dangerous for worker entry and $\mid$ Jviding a basis for modifying retrieval strategies to efficiently and safely deal with sources. Also, the presence of strong gamma radiation may, in some cases, imply the presence of more dangerous neutron emitting species if the neutron emitters were disposed together with the gamma emitters.

An encapsulated Cs-137 gamma source will be installed in the Characterization Cell subsurface via a plastic access tube to serve as the target for radiation detection experiments. The prototype system will use a standard $\mathrm{NaI}$ broad band gamma ray detector, but will have capabilities for resolving different gamma ray energy bands. 
The specific objectives of the radioactive source detection exencises are:

- Develop a methodology for making measurements of ganma radiation for the purpose of detecting radioactive waste.

- Develop a methodology for interpreting these data to determine the following three characteristics of a radioactive waste: depth, location, and configuration (that is, point source, layer source, and volume source).

- Develop a basis for evaluating the uncertainty in the above parameters as determined from passive gamma ray measurements. Determine the parameters that influence this uncertainty.

\subsection{Technology Agreement}

The prototype Dig-face Characterization System is being developed through the support of the BWID program under Technical Task Plan (TTP) \# ID132003. 


\section{ORGANIZATION AND RESPONSIBILITIES}

The FY-93 dig-face characterization performance tests involve personnel from various organizations at the INEL, the DOE Grand Junction Project Office, and a private consultant. Key project personnel are listed in Figure 4 according to tasks and responsibilities. In addition to the listed BWID project manager. the BWID organization includes managers with responsibilities for coordinating various aspects of the dig-face performance tests as well as other piojects.

\subsection{Testing Responsibilities}

The BWID project manager will have ultimate responsibility in decision making during planning and testing. Should a safety concem arise, the project manager and a safety engineer will decide how to solve the problem and whether to terminate testing. If the testing takes longer than planned, the project manager has the authority to delay or defer testing to balance overall project objectives and milestones.

The principal investigator will direct all technical activities including preparation of the prototype system, checkout of the system before field deployment, and oversight of the field program and data analysis. The principal investigator will assure that procedures are followed and that collected data are verified and adequate to meet the objectives for the performance tests. The principal investigator has authority to modify field procedures as necessary to handle unforeseen circumstances, as long as these changes are consistent with the project objectives and properly documented as described in Section 6.2 below.

\subsection{Additional Required Support}

Additional support will be required to (a) place survey control near the experiment site. (b) excavate the experiment site to a desired overburden depth. (c) provide a 120 Vac power source near the site for the data acquisition system, and (d) excavate soil layers from the site to simulate retrieval operations.

Health physicist support will be required for the test involving the CS-137 radiation source. See Section 12 and Appendix B for additional information relevant to use of the radioactive source. 


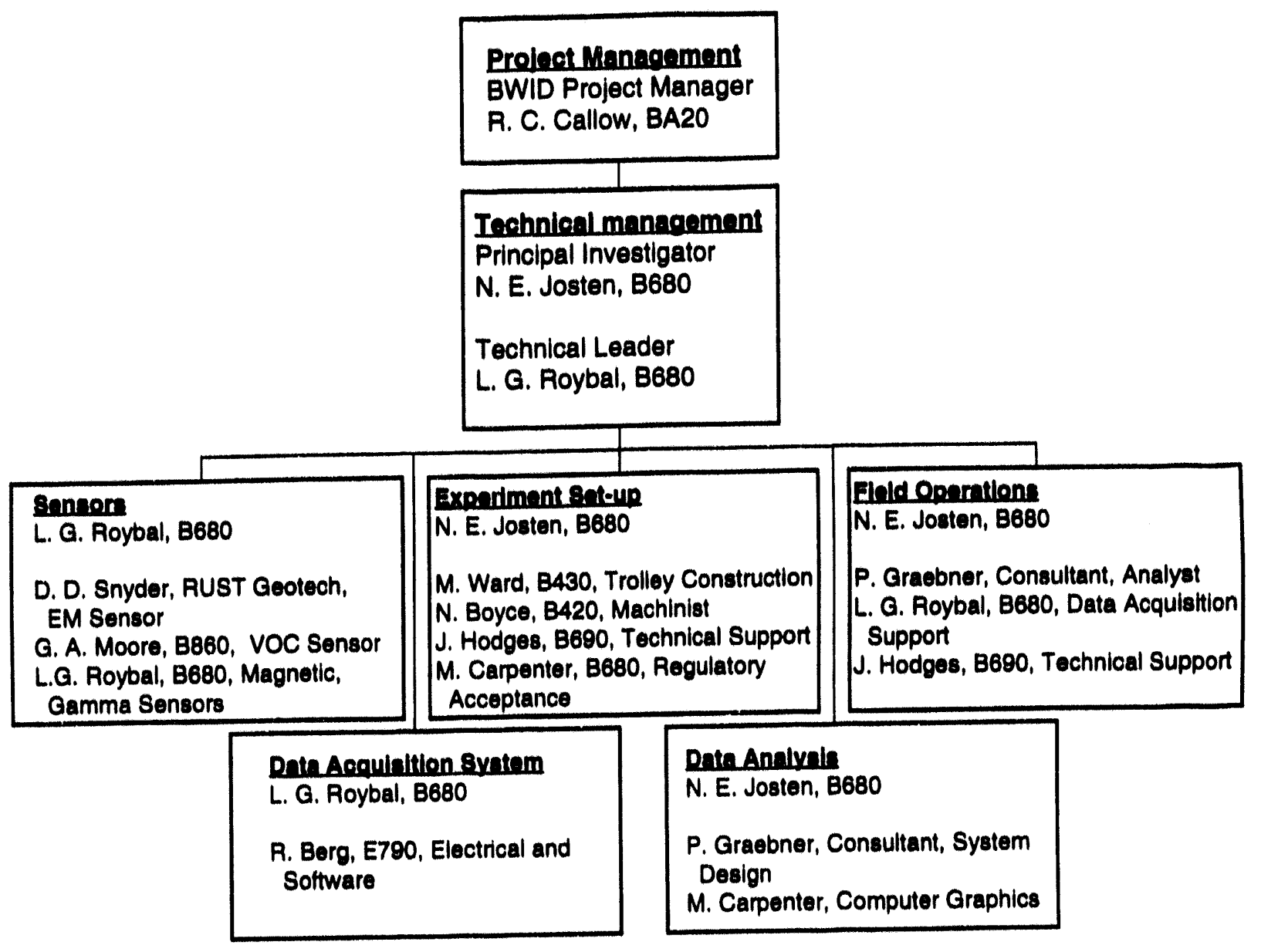

Figure 4. Summary of key project personnel for the Dig-Face Characterization project trench experiments. 


\subsection{Personnel Qualifications and Training}

Radiation worker training will be required for all personnel working within a marked exclusion zone at the test site during conduct of the radiation monitoring experiments.

Unescorted visitors to the test site will require blue card training. 


\section{DESCRIPTION OF TEST}

Performance testing of the prototype dig-face characterization system will take place at the Characterization Cell of the INEL Cold Test Pit (Figure 5). Separate tests will be conducted corresponding with the specific objectives listed in Section 1.4. A general description of the performance testing strategy is given below. Detailed procedures are provided in Appendix $C$. If time permits, additional targets will be buried adjacent to the Characterization Cell for purposes of conducting more complex testing. The proposed configuration of these targets is described in Appendix D.

\subsection{Test Strategy}

The performance testing described in this test plan follows a simple strategy: make detailed sensor measurements during simulated retrieval of buried waste on a scale that imitates the conditions at a real hazardous site and evaluate capabilities for determining the location and identity of waste objects as excavation proceeds. Because the tests will simulate actual hazardous site conditions, test results can be used to predict the performance of a Dig-Face Characterization System under working conditions.

Unique features of a dig-face characterization are: (a) measurements can be easily made at very fine grid intervals using the trolley structure, (b) measurements are made from multiple planes as the dig-face advances, and (c) measurements are made from close-up viewpoints just before the materials are exposed and retrieved. The performance tests are designed to fully capture these aspects of dig-face characterization. Simulated retrieval will proceed as a series of thin layer excavations of the Characterization Cell. Detailed sensor scans will be conducted at each successive excavation level using the prototype Dig-Face Characterization System. Scans will be alternated with excavation until the objects in the Characterization Cell are exposed.

The test data will be carefully examined to identify changes in sensor response that occur as the digface advances and the sensor viewpoint becomes progressively closer to the targets. By comparing the observed changes with the known location of buried objects, a set of indicators will be developed, which serve as keys for estimating the depth, location, and identity of the buried materials. Adjustments to data collection procedures will be made to enhance the clarity of the identified indicators. Additional tests may be conducted to evaluate performance of these indicators with respect to different environmental parameters as a means to begin assessing uncertainty issues. Through continued iteration of this approach, capabilities of the prototype dig-face characterization system, with respect to the test objectives, can be straightforwardly assessed. 


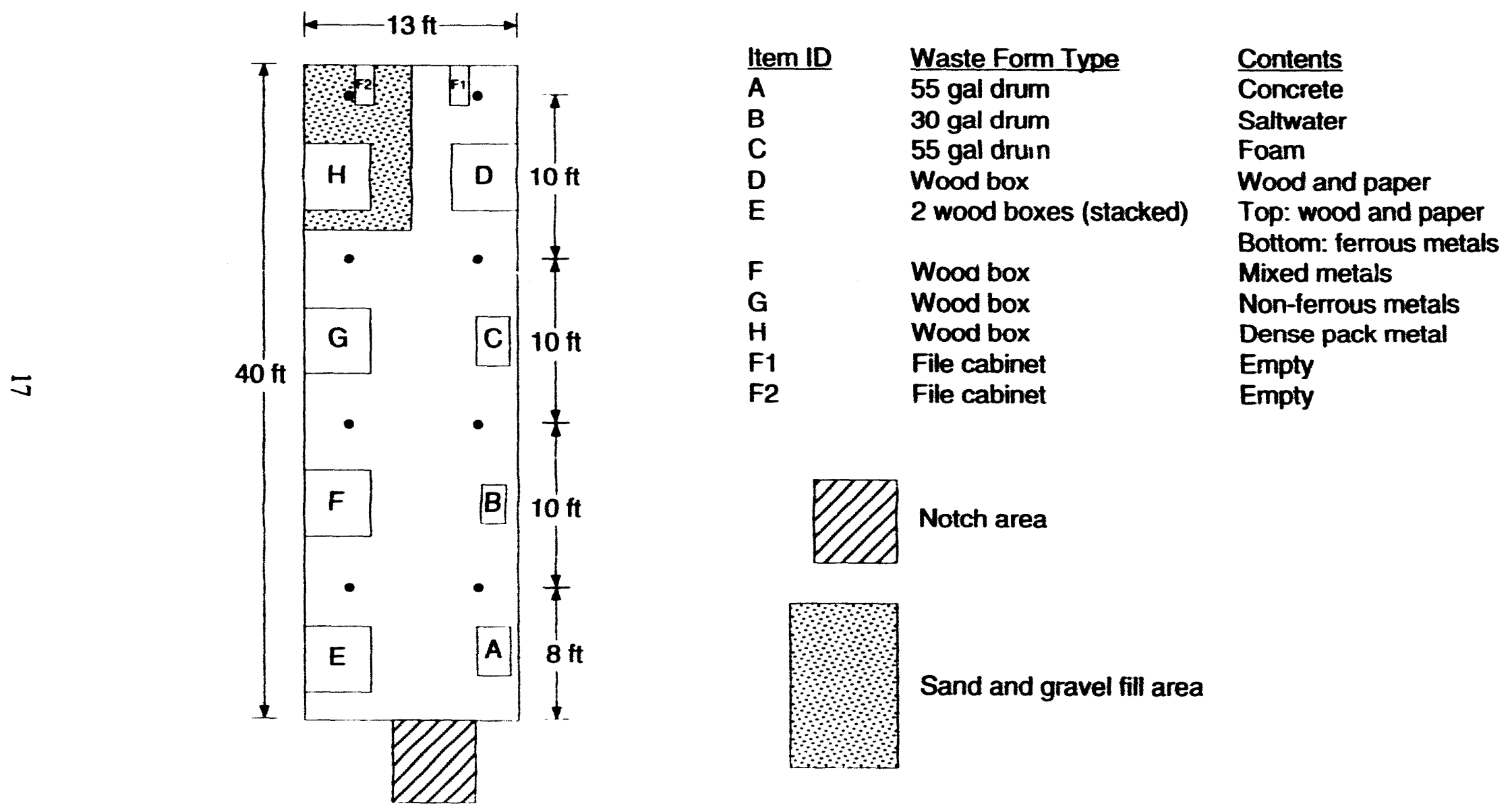

Figure 5. Diagram showing the Characterization Cell at the INEL Cold Test Pit. (Based on drawings
from Winberg 1992). 
The steps required to achieve the test objectives may be summarized as follows:

- Collect and store full dig-face characterization data sets.

- Develop quantitative conclusions regarding the detectability of each objective condition listed in Section 1.4 including

1. Point at which positive detection and identification are possible

2. Parameters that affect detection and identfication such as station spacing and soll type

3. Uncertainties in determining detection and identification points

- Develop and show an analysis approach supporting Item 2.

Testing will focus on three separate characterization problems: (1) detecting metal and Idenufying containers or large unusual objects, (2) detecting and identifying contaminant plumes in the soll, and (3) locating radiation sources. A more detailed discussion of these tests is presented below.

\subsubsection{Metal Detection}

Performance testing with magnetometers and an electromagnetic conductivity meter will focus on metal detection capabilities. The specific objectives are given in Section 1.4. In an actual site cleanup scenario, the presence of metallic objects can influence management of a retrieval effon in several ways:

- The presence of metal containers often implies the presence of hazardous materials

- Large or heavy metallic objects may require special equipment for handling

- The depth to metallic objects will often provide the most reliable and straightforward approach for estimating overburden depth.

We will investigate capabilities for locating and identifying containers, distinguishing large or heavy objects, and estimating object depths by applying the prototype Dig-Face Characterization System during step-wise excavation of various containers within the Characterization Cell. If possible, additional targets may be buried to validate and/or modify initial conclusions as described in Appendix $D$. The 
characterization surveys will be made using magnetic and electromagnetic measurements. Responses will be reconded for both sensors on a detailed grid as a function of soil depth and location.

\subsubsection{Plume Detection}

An electromagnetic conductivity meter and a photo-ionization based trace gas analyzer will be used to evaluate contaminant plume detection capabilities. The specific objectives of these tests are given in Section 1.4. During actual retrieval, the presence of contaminant plumes can influence management of a retrieval effort in two ways:

1. The presence of a contaminant plume in overburden may require modified handling and treatment procedures because overburden is normally assumed to be clean

2. The presence of a contaminant plume within the waste seam raises concems for workers who may need to enter the site to perform maintenance and creates the potential for cross contamination if the contaminants become airborne or are otherwise spread by the retrieval effort.

We will investigate capabilities for detecting plumes in an overburden-type setting by applying the prototype Dig-Face Characterization System over an area where a nonhazardous, organic volatile liquid (isopropyl alcohol) and a nonvolatile nductive liquid (dilute saline solution) have been introduced into the subsurface. The characterization surveys will be made using the conductivity meter and the trace gas analyzer, with responses recorded for both sensors as a function of soil depth and location.

\subsubsection{Radiation Source Detection}

A passive gamma ray sensor will be used to evaluate capabilities for locating and detecting radioactive sources in the subsurface. The specific objectives of these tests are given in Section 1.4. For purposes of managing a waste retrieval effort, gamma radiation sources create concerns exactly analogous to those stated in Section 3.1.2 for contaminant plumes. We will investigate the capabilities for detecting radioactive sources by implementing the prototype Dig-Face Characterization System over a retrievable, contained Cs-137 source placed at a known depth belowground. Gamma ray spectra will be recorded as a function of soil depth and location. 


\subsection{Uncertainty Considerations}

Factors affecting the uncertainty in determining characteristics of buried waste using magnetic, electromagnetic, gamma ray and photo-ionization sensors include

- Subjective nature of interpretation

- External noise

- Accuracy of sensor positioning

- Inherent accuracy of the sensors.

For typical waste sites, interpretation will likely create the largest element of uncertainty in waste site characterization. Complex sensor responses arising from the presence of numerous, diverse, closely spaced objects and materials within a heterogeneous soil medium will preclude the effective use of simple automated interpretation schemes. This places the burden of decision making on the subjective interpreter. This type of uncertainty is difficult (if not impossible) to quantify except in cases where interpretations may be verified by independent means. Simulated waste pits, in general, and the Characterization Cell, in particular, provide this opportunity because object identity and locations were recorded before burial. Uncertainty in the interpretation of the dig-face characterization data will be assessed through comparison of final interpreted results to known locations of objects in the Characterization Cell.

The performance tests have been designed to eliminate external noise sources. The Characterization Cell is located so as to eliminate all sources of cultural noise (such as vibration, fumes, and electromagnetic fields). The trolley is designed to be noninterfering with the planned sensor suite, and the data acquisition system will be located at a sufficient distance from the test cells to circumvent possible interference effects. External noise will be measured directly after initial setup of the trolley at the Characterization Cell as a means to verify noise-free operation. The final report will document results of these measurements.

The remaining factors affecting uncertainty relate to the quality or "correctness" of the sensor data. Of the two factors affecting sensor data quality, the inherent accuracy of the sensors is normally insignificant, provided that the sensors function properly. For the dig-face characterization performance 
tests, proper sensor function will be evaluated through calibration procedures, repeatability tests, and visual validation (see Sections 8 and 9).

The second and more important factor affecting sensor data quality relates to positioning. Positioning uncertainty results from imprecise tracking and recording of sensor location and from spatial undersampling. The trolley that will be used to position the dig-face sensors has been constructed to provide a position accuracy of approximately \pm 1 inch in three directions. Correct performance of the trolley will be evaluated by calibration procedures, repeatability tests, and visual validation (see Sections 8 and 9). Using the trolley, dig-face characterization data can be collected on grids as fine as 2 - 3 in. This makes it possible to adjust data acquisition as necessary to close data gaps, thus avoiding errors resulting from undersampling.

By eliminating the more easily controlled sources of uncertainty, the tests will focus on the problem of interpreting the characterization data with full confidence that the data relate to buried target materials, not to noise sources.

\subsection{Contingency Plans}

Tests will be discontinued in the event of weather conditions that compromise personnel safety, equipment, or test results. The BWID project manager will then evaluate the situation to determine the most appropriate method to meet the test objectives.

In the event that dig-face characterization performance testing deviates from this test plan, test procedures will be modified. Any modification of procedures will be performed in accordance with BWID requirements as described in Section 6.2. 


\section{SEQUENCE OF ACTIVITIES}

Appendix $\mathrm{C}$ lists the detailed sequence of activities for the dig-face characterrization performance tests. The basic sequence of events will be as follows:

1. Assemble and test the data acquisition system including trolley, PC-based data acquisition system, software, and sensors in Idaho Falls, ID.

2. Transport equipment to site, reassemble, and retest.

3. Perform data collection at the Characterization Cell of the INEL Cold Test Pit to evaluate metal detection capabilities.

4. Introduce a nonhazardous volatile organic liquid (isopropyl alcohol) and a nonvolatile conductive liquid (dilute saline solution) into the Characterization Cell subsurface and collect data to evaluate plume detection capabilities.

5. Emplace a retrievable Cs-137 radiation source and collect data to evaluate radiation source detection capabilities.

6. If schedule permits, bury additional targets and collect data to verify or extend results from the main experiments.

7. Conduct detailed data analysis in Idaho Falls, ID.

8. Write the final report. 


\section{DATA COLLECTION}

Detailed data collection procedures are described in Appendix B. The primary variable in data collection will be the sample spacings $\Delta x, \Delta y$, and $\Delta z$. After setting up the trolley over a test area (Figure 6), a written data acquisition plan defining sample spacing will be recorded in a field notebook. The initial plan will be to collect data on a 6-in. grid, both in the vertical and horizontal directions $(\Delta x=\Delta y=$ $\Delta z=6$ in.) for each sensor. This plan may be modified for different sensors, different tests, or based on new results. If the plan is modified, the new $\Delta x, \Delta y$, and $\Delta z$ values will be recorded.

The cell survey will proceed in a series of elevation steps, beginning with a survey of the air space above the undisturbed ground. Sensors will first be profiled across the pit, making measurements every $\Delta x$. The trolley span will then be moved $\Delta y$ along the pit, followed by collection of a new $\Delta x$ profile. After surveying in this manner with all applicable sensors, the sensor height is changed by $\Delta z$ (Figure 7).

Once the airspace above the cell has been surveyed, soil removal will begin, with layers removed in 6 in. to 1 foot increments. After each step of soil removal, a new sensor elevation will be set and the survey will continue. When buried objects are encountered, their position will be measured and recorded in field notebooks before removal.

All data will be displayed on a computer screen as they are collected. An engineer will monitor the data to make certain that sensors are operating properly. The data will be stored initially in mass storage and backed up on tape at convenient intervals.

At the end of each day, the data will be transferred from mass storage into a data base. This data base will be designed to facilitate data access during data analysis. 

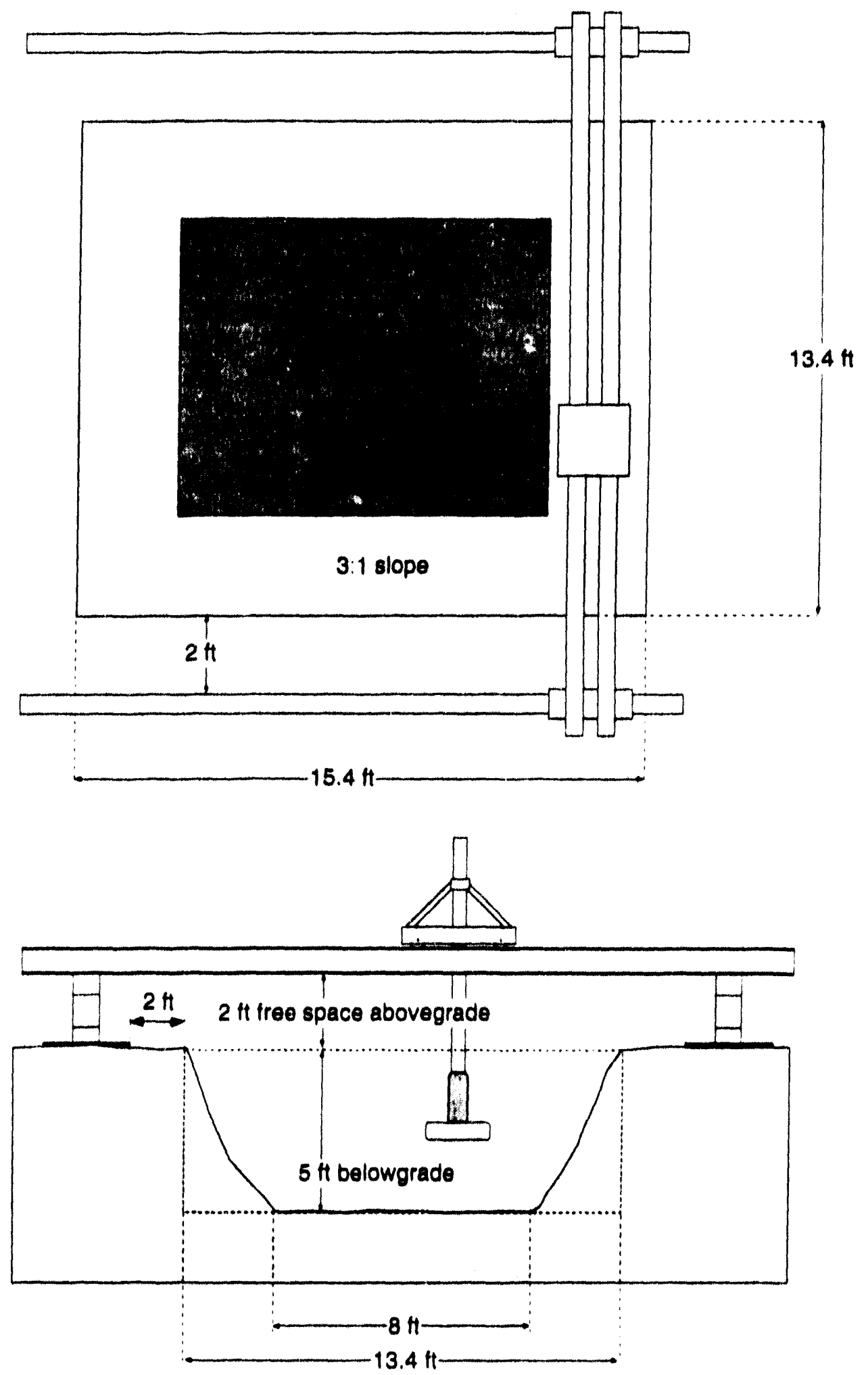

Figure 6. Schematic drawing showing setup of the trolley over a test cell. Drawing shows the approximate working range of the trolley in feet. 

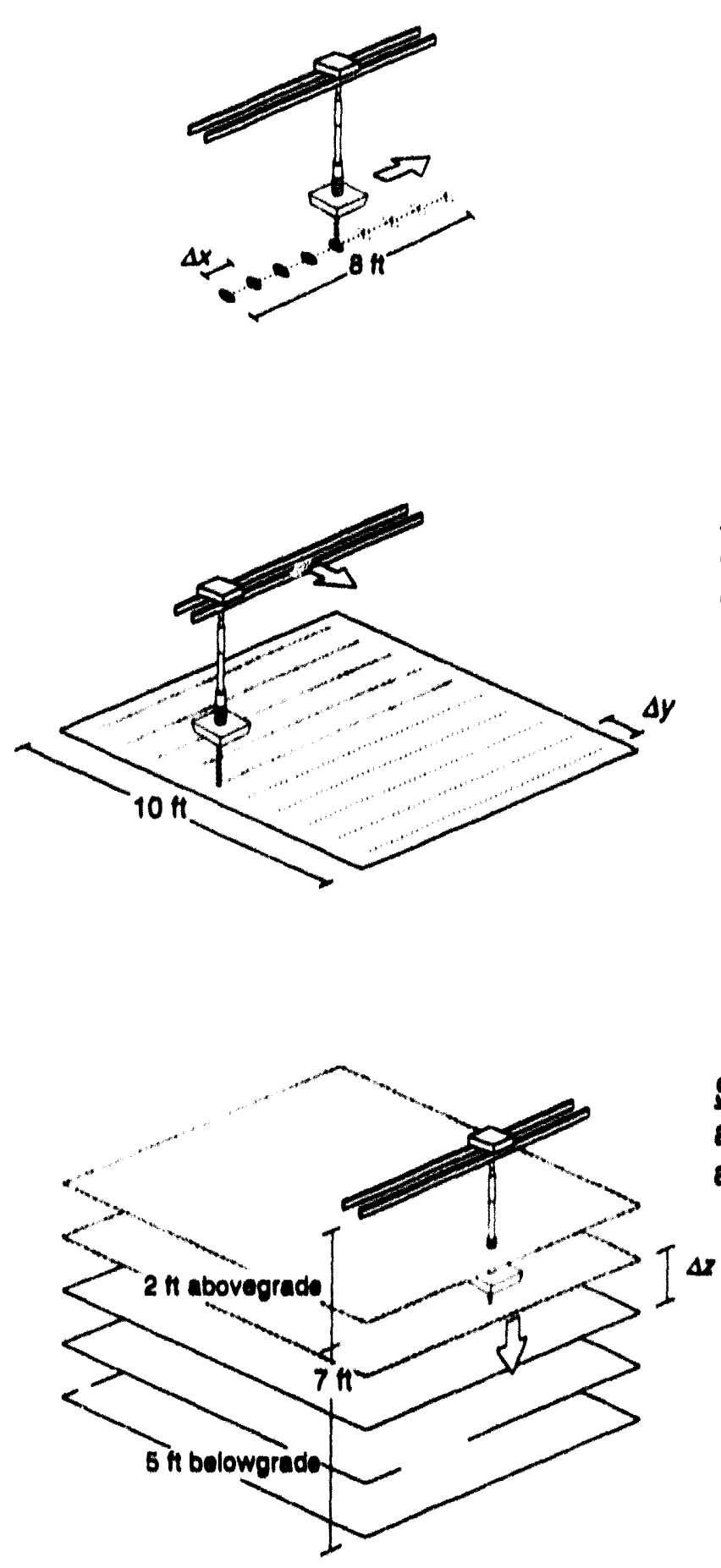

Figure 7. Illustration of the sequence of trolley motions required to collect three dimensional dig-face characterization data. Note the definitions of the data acquisition parameters $\Delta x, \Delta y$, and $\Delta z$.

\section{Surveving alaver
at 6 inch spacing -357 data points
at 12 inch spacing -89 data points \\ Sunquino alayer
at 6 inch spacing - 357 data points
at 12 inch spacing - 89 data points}

Sunveving a profille

at 6 inch spacing - 17 data points

at 12 inch spacing - 9 data points

\section{Sunveving acell}

at 6 inch spacing - 6069 data points at 12 inch spacing - 891 data points 


\section{DOCUMENT CONTROL}

Proper documentation and document control will provide a concise audit trail of the progress and results of the project. Applied Geosciences provides a number of standard procedures and techniques for management of data and documents (EO\&O Idaho 1992a). The specifics of these procedures are discussed below.

\subsection{Data Configuration Management}

The dig-face characterization performance tests will generate a large volume of data over a four week time period. A data acquisition system has been specifically designed to automate much of the data collection and formatting. The data acquisition system acquires and converts raw sensor output (e.8. voltages) to digital values in appropriate units, places a position stump on the data, and writes the resull to permanent storage in the appropriate format for later data processing and image generation.

The data will be incrementally archived onto floppy diskettes each day. The data acquisition system Is equipped with a $250 \mathrm{MB}$ tape backup unit that will be used to perform a total backup of data at the end of each week. These data will be transported and stored at the Research Office Building in Idaho Falls. ID. Once testing is complete, a copy of all datu and logbooks will be delivered to BWID.

\subsection{Test Plan}

Major changes to this test plan can be made before the field work. subject to approval by the BWID project manager. These changes will be in writing and altached to the front of the original test plan with the required approval signatures. A designaled master copy containing the original lest plan and all subsequent revisions will be located in the field with the lest apparatus. The principal investigator or * designated altemate may modify the test plan to account for unanticipated conditions that might occur during the experiments. These changes will be documented by striking out and adding the appropriate text to the master copy of the test plan. All such changes to the test plan will be reponed to the BWID project manager at the end of the day.

\subsection{Reporting and Logbooks}

Applied Gensciences has established a project file that contains a chronology of all official documentation (Interoffice Correspondence. Purchase Orders, etc.) associated with the Dig.Face Characierization Projecl. 
A master field Logbook will be kept by the principal investigator (or designated altemate) and will conform to the practices described in the Applied Ceosciences Land Magnetic Surveys Standard Operating Procedures (EO\&G Idaho 1992a). Copies of all data and logbooks will be delivered to BWID for archiving.

Final documentation of the experimental results will be included in the FY.93 Dig.Face Chancterization Project Final Report. This report will be issued in EO\&O Idaho Informal Report formal and adhere to the Company guidelines for this report format. 


\section{ANALYTICAL METHODS}

Not applicable. 


\section{DATA REDUCTION, VALIDATION, AND VERIFICATION}

Most data reduction for this effor will be done automatically by the computer based data acquisition system. This involves conversion of raw sensor output (volts) to a digital value in the appropriate engineering units. Analog output ranges and conversion factors for the sensors to be used in the perfomance testing are listed in Table 1. Detalled information on these sensors has been complled into Appendix A.

\subsection{Data Validation and Verification}

Sensor calibration is an extremely important element of the dig-face characterization concept. As described in the conceptual design document for the prototype Dig-face Characterization System (Josten 1992). the capability for bullding a vast data base of case histories on hazard detection and hazard identiflcation is buili into the envisioned technology. This data base, which will ultimately contain thousands of examples relating sensor responses to subsurface hazards for many different siles. can provide a vital aid during interpretation of new data at a new site. The uscfulness of these case histories will depend, in parn, on the mainienance of strict calibration requirements so that data collected at one site at one time can serve as a valid precedent for data collected at another site at a later time.

The issue of long term calibration is a complex one, and cannot be wholly addressed within the scope of the FY.93 lesting. However, this test plan stipulates calibration procedures that are adequate to ensure that all data collected during the FY.93 tests are valid for purposes of achieving the stated lest objectives. These procedures address iwo aspects of calibration: measurement stability and relative accuracy.

Sensor stability refers to the properiy of a sensor that causes if to always oulpul the same response when at the same location und under the same conditions, such that no component of the response is time variable. Temperature fluctuations and electronic drift are common sources of sensor instability, which can cause poor repeatability. Of the four sensors listed in Table 1, only the EM38 requires periodic reset of the electronics to counteract electronic drift. The remaining sensors are elther factory or laboratory calibrated. As a consequence, the EM38 will be callbrated according to manufacturer procedures at a designated calibration station iwice daily. In addition, repeat surveys of small areas will be conducted at least Iwice daily with all sensors in regular use for that day and ambient temperature and humidity will be recorded at regular intervals. While these procedures do not arrest instrument drift, they provide a means to recognize its presence and severity. 
In the present context, relative accuracy refers to the property of a sensor that causes it to respond properly as the sensor is moved about within the volume of influence sumbunding materials to which that sensor is sensitive. This may be contrasted with absolute accuracy, which can only be established by testing the instrument over its full range through comparison with known standards. For the dig-face characterization tests, relative accuracy (or data validation) will rely primarlly on the past experience of the operators. A visual inspection of the data will be performed to insure that the data are reasonable as compared to previously encountered stmilar conditions. The data acquisition system will have online data display capabilities to facilitate data validation during the tests. Visual inspection will be done by the technical field leader or other designee. The data acquisition system also provides direct waming when input analog voltage from any of the sensors equals or exceeds the manufacturer recommended range for correct operation.

Validation of position data will be performed using distance scale marks etched onto the main structural beams of the manual trolley. Electronic position will be compared against the physical position of the trolley by reference to the etched scales. Position validation will be performed at least once following each change of the z-position of the trolley. Accuracy and repeatability of the trolley will be independently assessed by placing reference survey stakes in the test cell at known locations at least once following assembly of the trolley at a new location. The known positions of these reference stakes will be compared to the electronic readout of position provided by the delivery system.

Data verification involves ensuring that the data are transcribed correctly during transfer from one media to another. Because the data will be handled entirely by electronic means, the data verification process is minimized. Copies of raw sensor output will be maintained permanently, providing a means to verify any or all portions of the data set at any time. Trolley position, date, and time of day will remain permanently stored with each unit of raw sensor output. 
Table 1. Operating parameters and conversion factors for dig-face characterization sensors.

\begin{tabular}{|c|c|c|c|c|}
\hline Sensor & Manufacture and model & Opernting range & Analog output & Conversion factor \\
\hline Magnetometer & $\begin{array}{l}\text { Electro Mechanical Design } \\
\text { Services, Inc. } \\
\text { Model: ORS-1 Single Axis } \\
\text { Fluxgate Gradiometer }\end{array}$ & $\pm 330,000 \frac{\mathrm{nT}}{\mathrm{m}}$ & \pm 10 volts $(V)$ & $1 V=32808 \frac{n T}{m}$ \\
\hline Conductivity & $\begin{array}{l}\text { Geonics, Limited } \\
\text { Model: EM38 Ground } \\
\text { Conductivity Meter }\end{array}$ & $\begin{array}{l}0.1000^{\frac{m m h o}{m}} \\
\pm 36 \mathrm{ppm}^{6}\end{array}$ & $\begin{array}{l} \pm 250 \text { millivolts } \\
(\mathrm{mV})\end{array}$ & $\begin{array}{l}1 \mathrm{mV}=4 \frac{\mathrm{mmho}}{\mathrm{m}} \\
1 \mathrm{mV}=0.144 \mathrm{ppm}\end{array}$ \\
\hline $\begin{array}{l}\text { Trace gas } \\
\text { analyzer }\end{array}$ & $\begin{array}{l}\text { HNU Systems, Inc. } \\
\text { Model: DL-101 Portable } \\
\text { Photoionization Detector }\end{array}$ & $0.1 \cdot 2000^{\circ} \mathrm{ppm}$ & $0.2 \mathrm{~V}$ & $1 \mathrm{~V}=1000 \mathrm{ppm}$ \\
\hline $\begin{array}{l}\text { Gamma ray } \\
\text { detector }\end{array}$ & $\begin{array}{l}\text { Eberline Corporation } \\
\text { Model: ASP.) Survey Instrument } \\
\text { w/ INEL installed Nal detector } \\
\text { element }\end{array}$ & $0.35 .000 \frac{\text { counts }}{\mathrm{s}}$ & $0.2 V^{d}$ & $1 V=17,500 \frac{\text { councs }}{s}$ \\
\hline \multicolumn{5}{|c|}{$\begin{array}{l}\text { a. Quadrature mode, maximum scale range. } \\
\text { b. Inphase mode, maximum scale range. } \\
\text { c. Based on benzene. } 10.2 \mathrm{eV} \text { lamp. } \\
\text { d. Depends on final detector installation. }\end{array}$} \\
\hline
\end{tabular}




\section{QUALITY ASSURANCE}

This effon will be performed in accordance with the requirements of quallty level B as defined in the EG\&O Idaho Quality Manual (EG\&O Idaho 1992b).

\subsection{General Quality Control Methods}

Quality control $(\mathrm{QC})$ can be maintained by establishing that the experimental hardware is in proper working order before testing and that sensors are responding properly during conduct of teuting. Senuor response is addressed in Section 8 of this test plan, describing data valldation procedures. Correct hardware functionality can be assured by performing a visual inspection of the sensor delivery aystem and data acquistition system at the beginning and end of each day. This inspection will concentrate on abnormal wear on mechanical components and integrity of all electrical connections. Because the teats will occur in outdoor conditions, the general cleanliness of the equipment will be assesced and proper cleanup and preventative maintenance will be done as required. This may involve removing dust with compressed air equipment and lubrication of moving parts.

Should the equipment malfunction, or an abnormal operating condition occur, field operations will be suspended until the problem is resolved. If the problem is considered minor, field operation may continue at the discretion of the technical fleld leader(s). An example of this scenario would be fallure of one of the GRS.1 gradiometers. Here, field operations would continue with the remaining gradiometers.

\subsection{Specific Quality Control Procedures}

The dig-face characterization performance testing will adopt a set of specific QC procedures that will govern all data acquisition. The five QC procedures for dig-face characterization performance testing are stated as follows:

1. Data collected during performance testing will be within the manufacturer recommended operating range for each sensor; data falling outside this range will be nagged immediately by the data acquisition system or by field personnel

2. The EM38 will be calibrated twice dally at a designated calibration station when it is in regular use 
3. Repeatability of all sensors will be monitored by duplicating data acquisition along a selected data profile at least twice daily for all sensors in regular use for that day

4. Proper function of the trolley positioning system will be monitored by comparing the electronic position against the physical position (through reference to scale marks) at least once following each change in the $\mathrm{z}$ fosition of the trolley

5. Following assembly of the trolley at a new location, accuracy of the trolley positioning system will be assessed by placing reference survey stakes in the test cell at known locations and comparing the known positions of these reference stakes to the electronic readout of position provided by the trolley. 


\section{EQUIPMENT AND INSTRUMENTS}

The equipment required for the dig-face characterization tests is provided from within the Dig Face Characterization Project. The major pieces include the overhead trolley sensor delivery system, the personal computer (PC) based data acquisition system, and the sensor subsystems. The responsible parties for providing the various pieces of equipment are listed in Table 2. A description of each of these pieces of equipment, including specifications, is provided in Appendix A. 
Table 2. Personnel/Equipment Matrix.

Equipment

Sensor delivery system

PC data acquisition system

Magnetometer subsystem

Electromagnetic subsystem

Trace gas detector

Gamma ray sensor
Responsible Party

M. Ward, EG\&G Idaho Mechanical Engineering

L.G. Roybal, EG\&G Idaho Applied Geosciences

L.G. Roybal, EG\&G Idaho Applied Geosciences

D.D. Snyder, RUST Geotech

G. A. Moore, EG\&G Idaho Materials Chemistry

L. G. Roybal, EG\&G Idaho Applied Geosciences 


\section{SUPPLIES, UTILITIES, AND FACILITIES}

Implementation of this test plan hinges upon the availability and support of personnel at the Cold Test Pit. This includes labor and/or equipment to prepare the site and to excavate the test cells to simulate a retrieval operation. Other site requirements include the availability of $120 \mathrm{Vac}$ power and a secure enclosure for housing the data acquisition equipment. 


\section{HEALTH AND SAFETY}

Except for operations involving use of a Cs-137 radiation source, no special health and safety issues apply to this test activity. The standard gatehouse and Hazards Communication training are required for all personnel on this Project. The EG\&G Idaho Safety Manual will govern all activities at the Cold Test Pit (EG\&G Idaho 1992c).

Health and safety issues related to radiation monitoring tests using the Cs- 137 source are presented in Appendix B. 


\section{RESIDUALS MANAGEMENT}

No hazardous wastes or residuals will be generated as a result of this activity. 


\section{REFERENCES}

Crof, K. M., R. A. Hyde, and S. M. Allen. 1993, "Dig-Face Characterization (DFC) Teat Plan - Remote Testing," Informal Repon EOG.WTD-10771, EO\&O Idaho.

EO\&G Idaho, 1992. Geosciencers Sundnad Opamine ProcedunerMnnunl. Applied Geosciences Unit.

EO\&O Idaho Healith and Srfaty Plan (see Appendix B. Section 12.0).

EO\&O Idaho Qunlity Manual (see Section 9.0).

Graebner, P. and N. Harthill, 1992, "Conceptual Design For a Dig Face Characterization Data Base and Data Analysis Subsystem." Ecology Internationa's Final Repont for EO\&O Idaho Subcontract C92-120383, EO\&O Idaho.

Josten N. E., 1992. "Preliminary Design For a Safe Step Remediation System." Intemal Technical Report EOG-EELS-002, EO\&O Idaho.

Mayberry, J. L., F. Feizollahi, and J. C. Del Signore, 1992. "Preliminary System Design Study Assessment Report", Infornal Repont EGG.WTD.9594. Volume 3, EG\&O Idaho.

Morrison, J. L.. 1993. "BWID Core System Requirements and Test Objectives," Draft letter WJL-01-93 to BWID. EG\&G Idaho.

Richardson. J. G., M. J. Rudin, M. C. O'Brien, J. L. Morrison, and B. Raivo, 1992, "INEL Operable Unit 7.13 Retrieva/Ex Situ Thermal Treatment Configuration Options," Informal Repon EOG-WTD. 10204, EG\&O Idaho.

Winberg. M. R., 1992, "Specifications of the Addition of a Characterization and a Retrieval Cell to the Cold Test Pit," Engineering Design File BWP.VSI-009, EG\&G Idaho. 


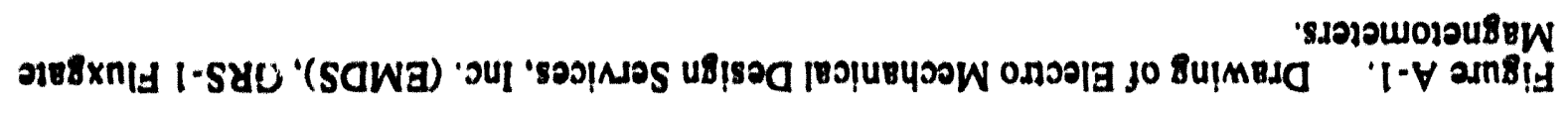

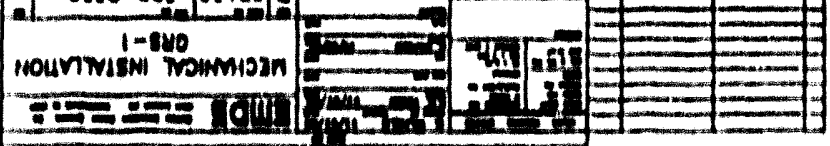

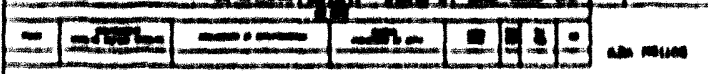
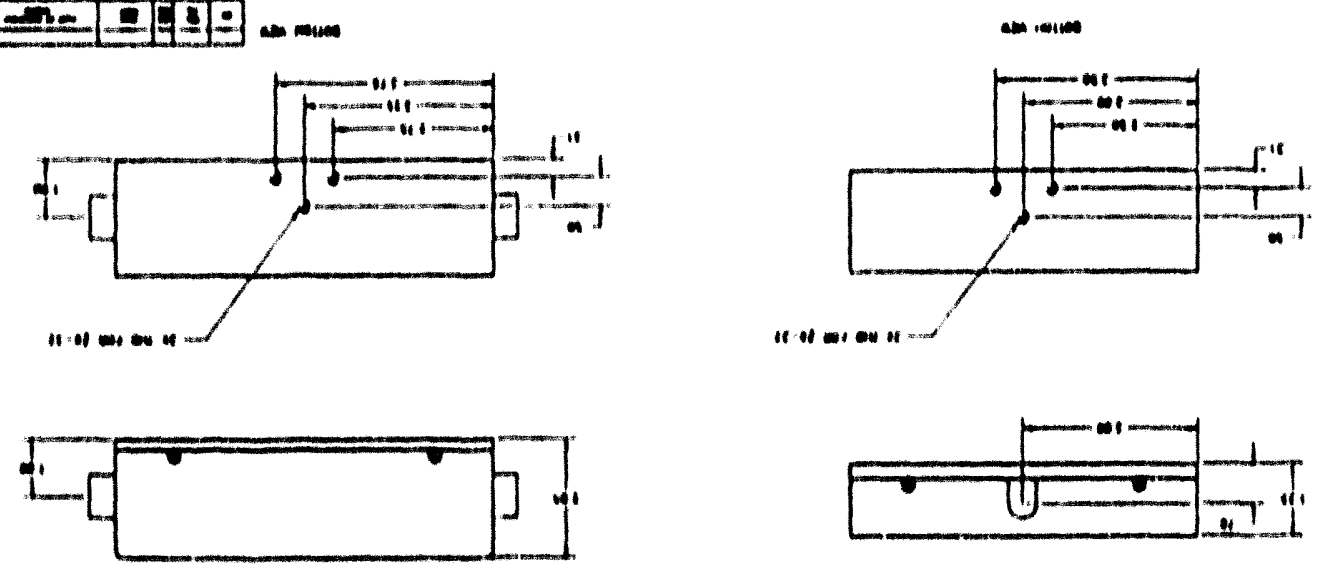

,

"
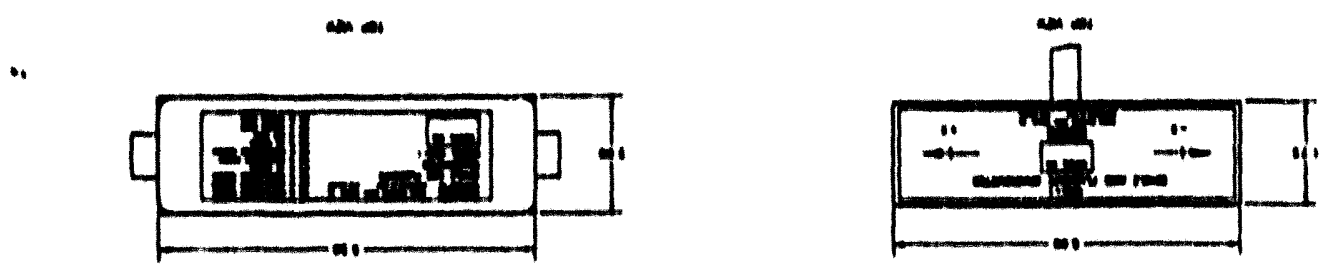

1

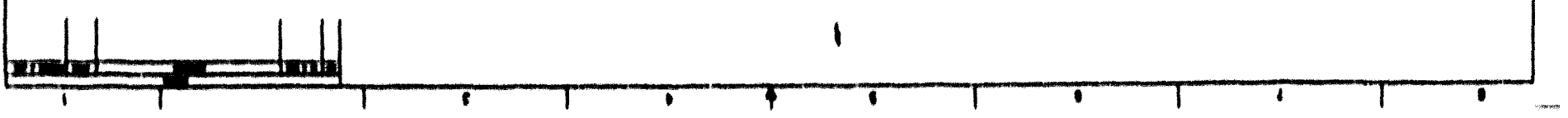

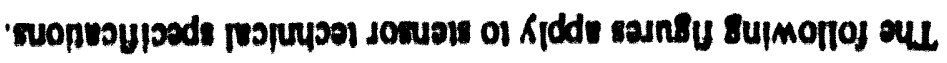

suoproupods foopuypol dosueg

V XIaNEddV 


\section{Instrument Spectifantions:}

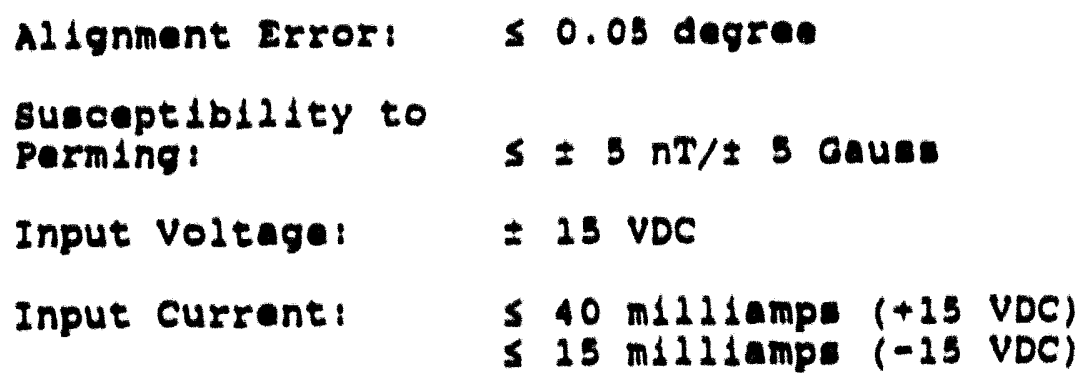

Figure A-2. Technical specifications of EMDS, GRS-1 Fluxgate Magnetometers. 


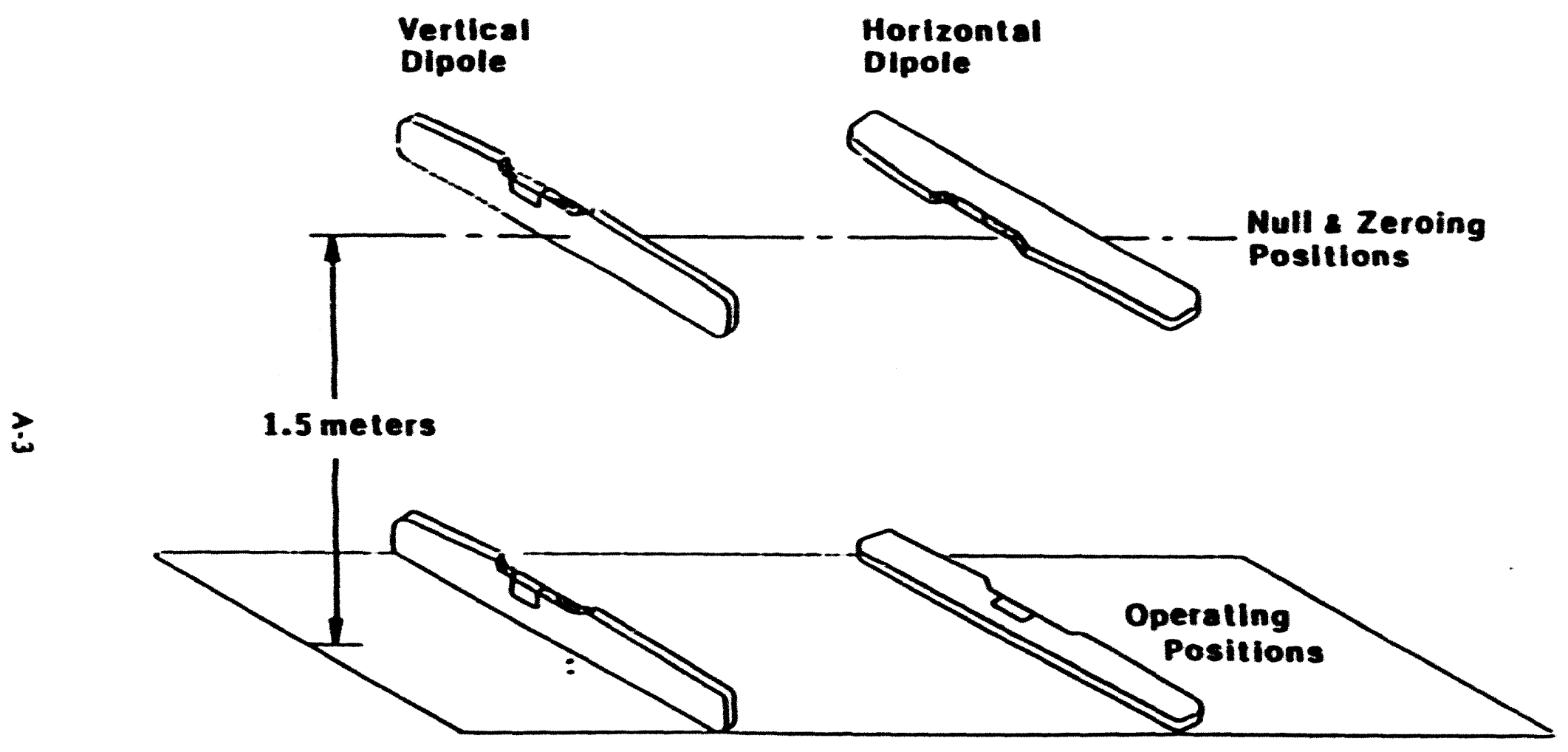

Figure A-3. Drawing of Geonies, Limited EM38 Ground Condectivity Meter. 


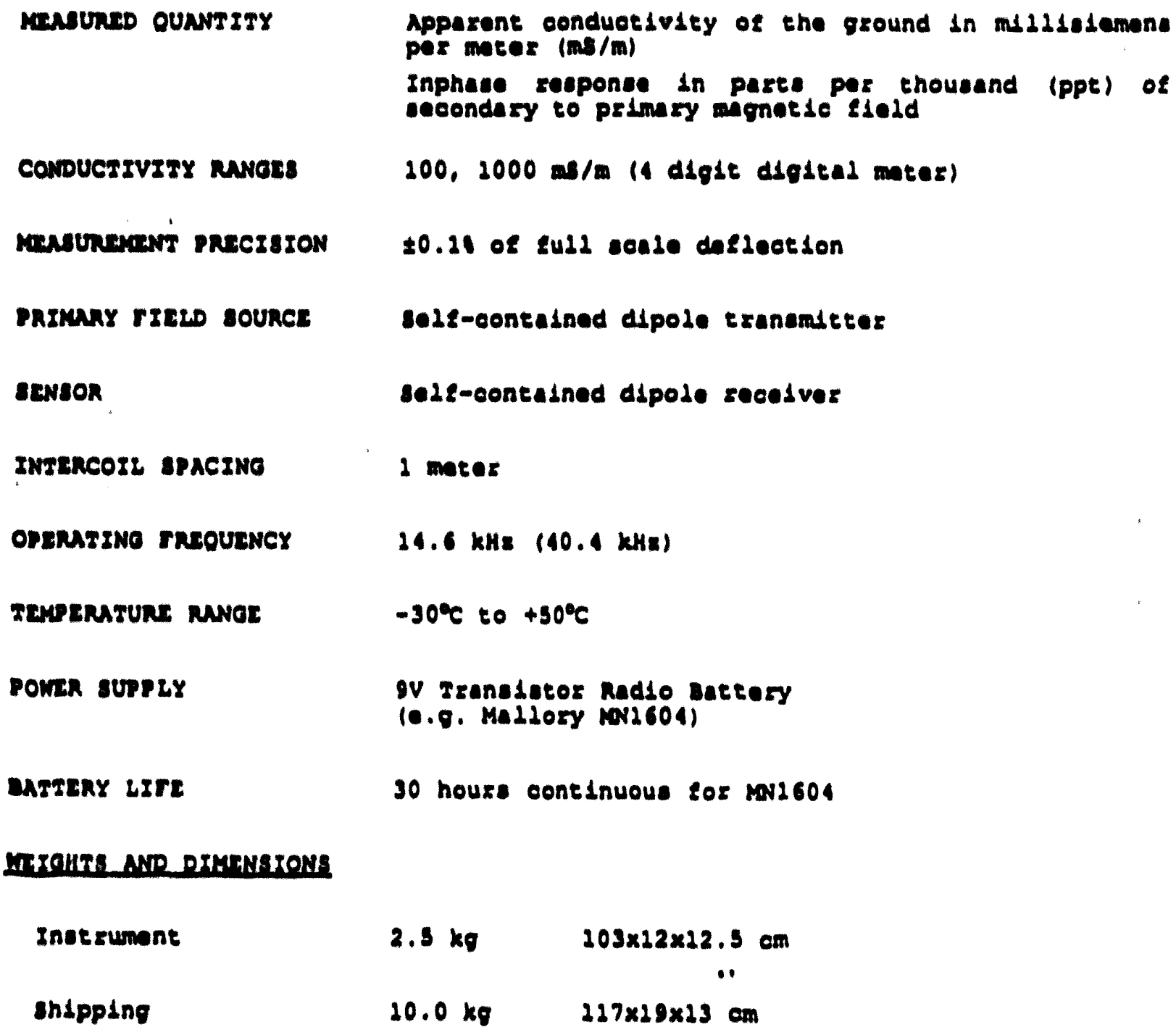

Figure A-4. Technical specifications of Geonics, Limited EM38 Ground Conductivity Meter. 


\section{SECTION TWO: STARTUP}

\subsection{UNPACKING}

To sel up the DL. 101, follow this procedure.

1. Take the unit nut of the box and unyip the lid of the shoulder bag to access the right side pancl and probe recepucle.

2. Remove the red cap plug from the end of the nozzle on the probe.

\subsection{PROBE CONNECTION}

1. Locate the probe peceptacle on the right of the control module (sce diagram).

2. Line up the red dol on the probe connector with the red dot on the receptacle.

NOTE: Probe conneclors are keyed and can only go in one way.

3. Push the connector straight in unul it clicks and locks in place. To verify that the connecuon is locked. pull on the connector struin reliel.

NOTE: Disconnecting the probe from the conurol modulc is accomplished by pulling out on the knurled par of the probe connector.
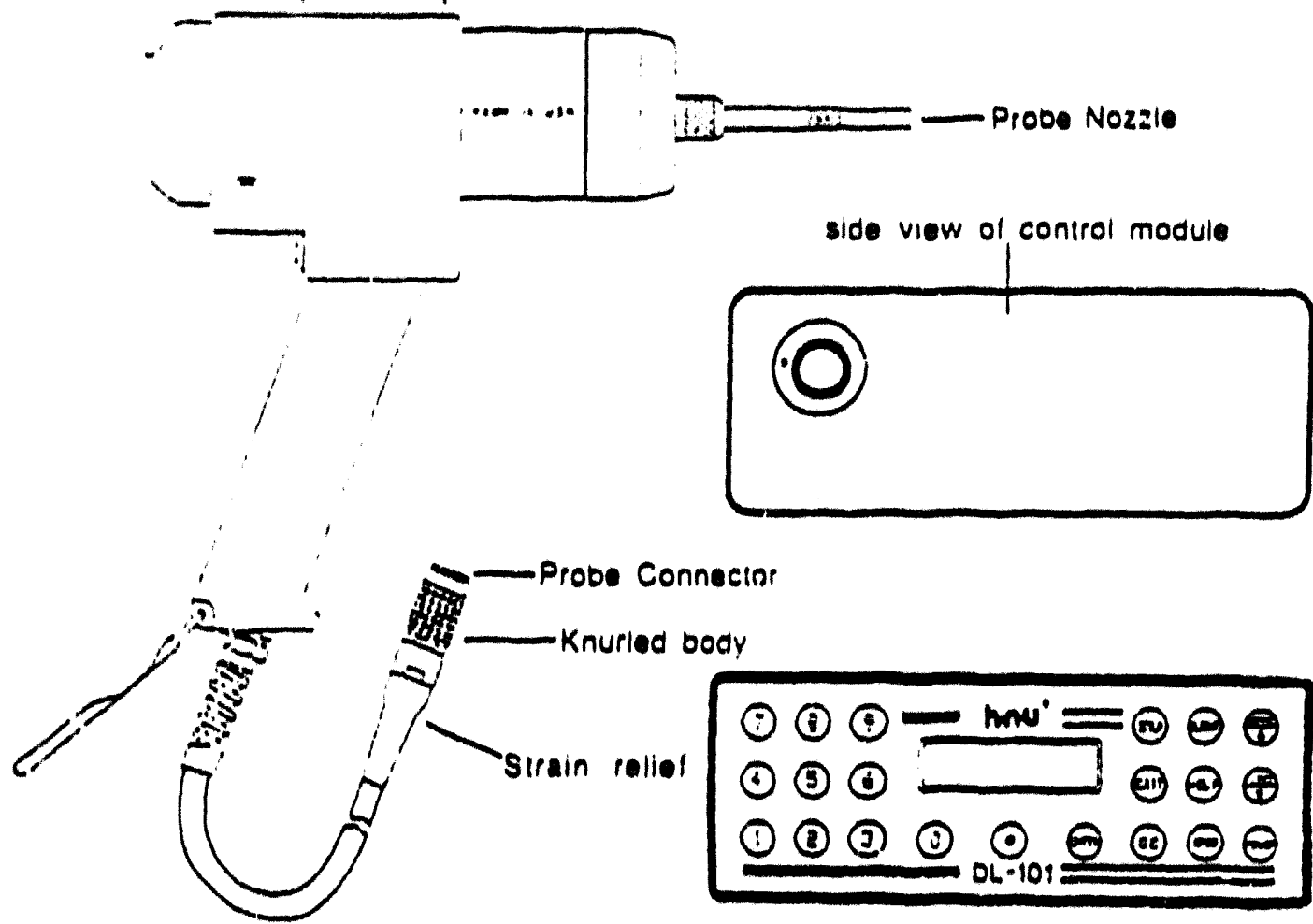

HNU Systems, Inc. DL-101 Operator's Manual

Figure A-5. Drawing of HNu Systems, Inc., DL-101 Portable Photo-ionization Detector. 


\title{
SECTION NINE: DL-101 PRODUCT SPECIFICATIONS
}

\author{
Cortification \\ designed to meet Class !. Division 11. Groups ABCD \\ Detection Principle \\ photoionizavion \\ -Range \\ $0.1102000 \mathrm{ppm}$ \\ - Linear Range \\ $0.110400 \mathrm{ppm}$ \\ - Dotection Limit \\ $0.1 \mathrm{ppm}$ \\ -Repeatability \\ $+1.1 \%$ \\ Response Time \\ $<3$ seconds $1090 \%$ response \\ Inlat flow \\ $225 \mathrm{cc} / \mathrm{min}$ \\ Ambient Humidity \\ $1095 \%$ RH (noncondensing) \\ Ambient Operating Temperature \\ $10400 \mathrm{C}$ (temperaure compensaled so that a $20^{\circ} \mathrm{C}$ \\ change in temperature cortesponds in reading of $<+1$. \\ $2 \%$ full seale at meximum sensiuvity) \\ Callbration \\ benzene referted defaull plus 11 user defined \\ calibrations \\ Interchangeable lamps \\ $11.7,10.2$, and $9.5 \mathrm{cV}$ \\ Dimensions \\ prote ( 8 in. $\times 3$ in.) \\ readout module $(8 \times 3 \times 6$ in.) \\ cable (36 in.) \\ Wolght \\ probe (3 lbs.) \\ readout module (4 lbs.) \\ lowal wecight ( $7 \mathrm{lbs}$.) \\ Oparating Time on Battery, \\ $>$ cight hours continuous use at $23^{\circ} \mathrm{C}$ \\ continuous use \\ Approximalely 6.4 hours al $O C$. \\ Recharge Time trom \\ full discharge \\ 121014 hours \\ $0-5$. hours \\ Recorder Output \\ $2 v+1.3 \%$ a $2000 \mathrm{ppm}$ \\ NOTE" When equipped with $10.2 \mathrm{cV}$ lamp and measuring benuene. Values vary for other compounds, \\ condicions, and lamp used. Use of multipoint eylibration can increase the linear range.

HNU Systems, Inc. DL-101 Operator's Manual $9-1$

Figure A-6. Technical Specifications of Eberline Corporation, ASP-1 Survey Instrument. 


\section{Analog Smart Portable}

\section{Model ASP.1}

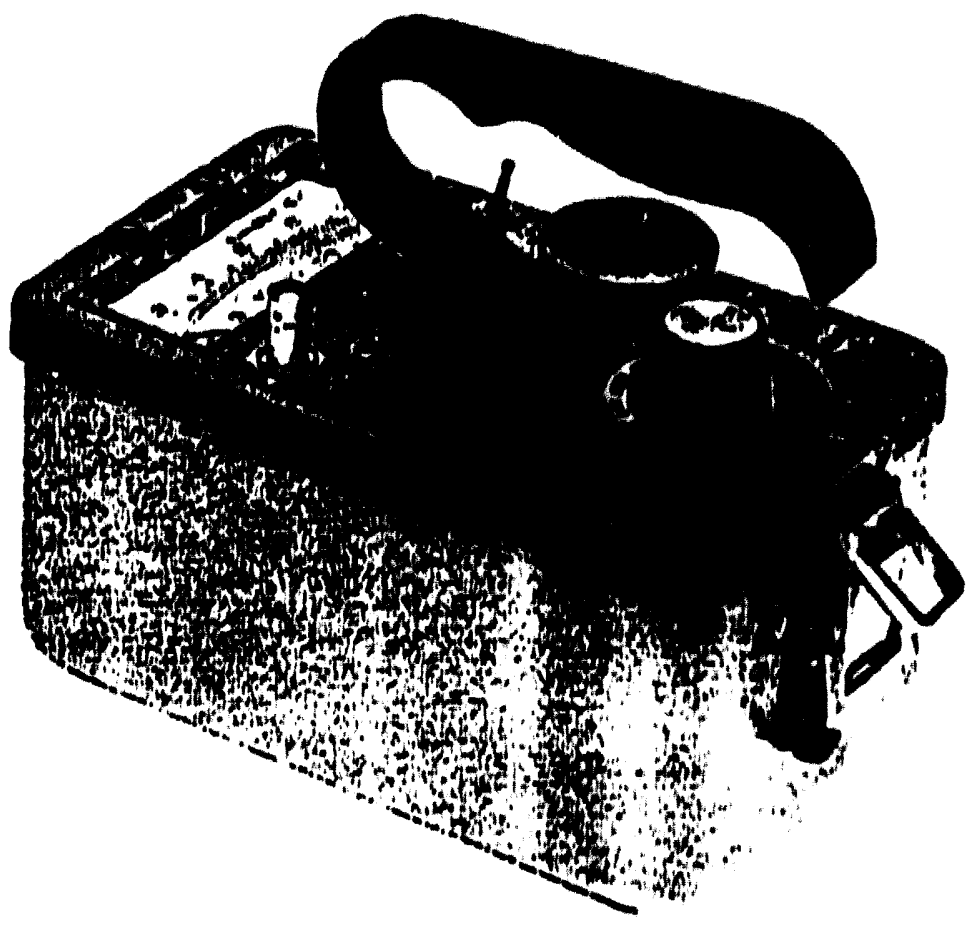

- OPERATES WITH EBERLINE DETECTOR PROLES TO

MEASURE ALPHA, BETA, OAMMA, X-RAY AND NEUTRON RADIATION

- OFFERS EXTENDED RANGE WITH AUTOMATIC DEAD.TIME CORRECTION

- RADIATION UNITS EASILY SELECTED EY THE USEA

- FUNCTIONS AS A RATE METER AND INTEORATOR

- BATTERY.SAVING CMOS MICROCOMPUTER

- OPTIONAL SINQLE.CHANNEL PULSE.HEIGHT ANALYZER (PHA) AND INTERNAL Q.M DETECTOR AVAILABLE

Figure A-7. Drawing of Eberline Corporation, ASP-1 Survey Instrument. 


\section{Model ASP-1, Analog Smart Portable}

\section{DENERAL DESCRIPTION}

The Eberline Analog Sman Portable (ASP. 1) is our most versatile, matered survey instrument. Designed for use with G.M, scintillation and proportional dotectors, It is capable of measuring alpha, beta, gamma, $x$-ray and noutron radiation.

The ASP- 1 functions as a rate metor and an integralor, and dleplays the present radiation rate or the integrated total radiation received.

Mlerocomputer-based, the ASP- 1 corrects for coincidence loss so that the uppor limit of the range of each detector is increased by a factor of ten or more. When the useful range is exceeded, an overrange alarm is given. The ASP. 1 has built-in spakar and head-set is provided tor use in nolsy areas.

When the ASP. 1 is used us a rate meter, the CMOS miorocomputer selects the appropriate response

\section{SPECIFICATIONS}

\section{Meter (lighted):}

Upper seale: 0 to 1.0.50 divislons (range determined by detector used)

Lower scale: 0 to $2500 \mathrm{~V}, 50$ divisions

Scale lengths: $7.6 \mathrm{~cm}$ ( $3 \mathrm{in}$.)

High Voltage Output: From 300 to $2500 \mathrm{~V}$ with no load and up to $1600 \mathrm{~V}$ with a $100 \mathrm{M} \Omega$ load.

Input Sensitivity:Adjustable from 1 to $50 \mathrm{mV}$, negative pulse.

Detector Dead-TIme Compensation: Up to $255 \mu 5$.

\section{External Control}

A nine.position rotary switch turns the ASP. 1 on, checks the batteries, displays the high voltage and eelects the range of operation. Three toggle switches control the speaker, the meter light, the reset function, the response time and the operating mode (rate or integrate). lime based on the count rate from the detector and the range switch position. Normal response lime ranges from one to ten seconds with a standard deviation (SD) no greater than five percent over the top three decades of the useful range. Longer response times, and better precision, can be selected.

Inventory savings can be significant by using the ASP-T. This instrument will perform the functions of many other radiation survey instruments when coupled with detector probes avallable as accessories. One detector probe can be used to measure gamma exposure rate, another to measure beta-gamma contamination, another to measure alpha contamination, and another to measure noutron dose equivalent. With appropriate deteotors, the ASP. 1 performs all functions of Eberline's E-120, E-130A, E-740, E-520, E-530, PNR-4, PRM-6 and PRM-7, combined.

\section{Operating Modes}

The ASP-1 continually computes the detector pulse rate and the total integrated count from the detector. When the response switch is set at SLOW or FAST. the meter displays the count rate in the calibrated units (mR/h, rom/min, cpm, etc.). When INTEGRATE is selected, the meter displays the total radi. ation received (in the same units of calibration, $m A$, rem, counts, etc.) since integration was last reset.

\section{Battery}

Six C-cell size batteries are used. The life of six carbon-zinc banteries is variable from about 150 to 250 hours, depending on the high voltage power required, the speaker usage and the light usage. Alkaline balleries will last more lian twice as long under the same operating conditions. The BAT position of the range switch checks the battery condition.

Figure A-8. Technical specifications of Eberline Corporation, ASP-1 Survey Instrument. 


\section{APPENDIX B \\ Procedures for Handling and Use of Cs-137 Source at the Cold Test Pit}

1. The Cs-137 source strength will be limited to $18.7 \mathrm{mCi}$. It will be used at the Characterization Cell of the INEL Cold Test Pit.

2. The source will be leak checked (smear) before leaving the Test Reactor Area (TRA) and again at the completion of use at the Cold Test Pit. The source is encapsulated in quartz which is placed inside a screw top test tube (glass), which is contained inside a PVCbrass source container (see Figure B-1).

3. The Cs-137 source will only be handled by qualified users.

4. The source will not be touched by hand. It will remain inside the test tube at all times at the experiment site. Metal tongs will be used to transfer the test tube containing the source from the shipping container to the PVC/brass source container and back again. All contact with the source container will be as brief as possible so as to minimize exposure. The source shall remain inside the PVC/brass source holder until it is transferred into the return shipping container.

5. The actual times when the source is handled will be logged on a separate sheet in the source log book. The source book will be maintained by the authorized user.

6. The Cs-137 source will be stored at TRA in its normal storage facility when not in use. It will be returned to TRA immediately after each day's use. If proper storage can be arranged at the Radioactive Waste Management Complex (RWMC), then return shipment to the TRA storage facility will not be initiated until the test series at the Cold Test Pit is complete. The source cabinet at RWMC is appropriately marked, showing that radioactive materials are contained within it.

7. During the experiment, the PVC/brass source container will be lowered inside a larger diameter PVC tube which is buried in the ground at the Cold Test Pit. The source will be tethered to a nylon cord which will be tied off at the surface. The source will be 
approximately $2 \mathrm{ft}$. beneath the ground surface and will be instantly retrievable whenever necessary.

8. Health physics coverage will be commensurate with guidelines specified in the "Radioactive Source Handling and Control" procedure (EG\&G Idaho Company Procedures Manual Volume 3, Section 10.18) and by the designated radcon technician (EG\&G Idaho 1993). 


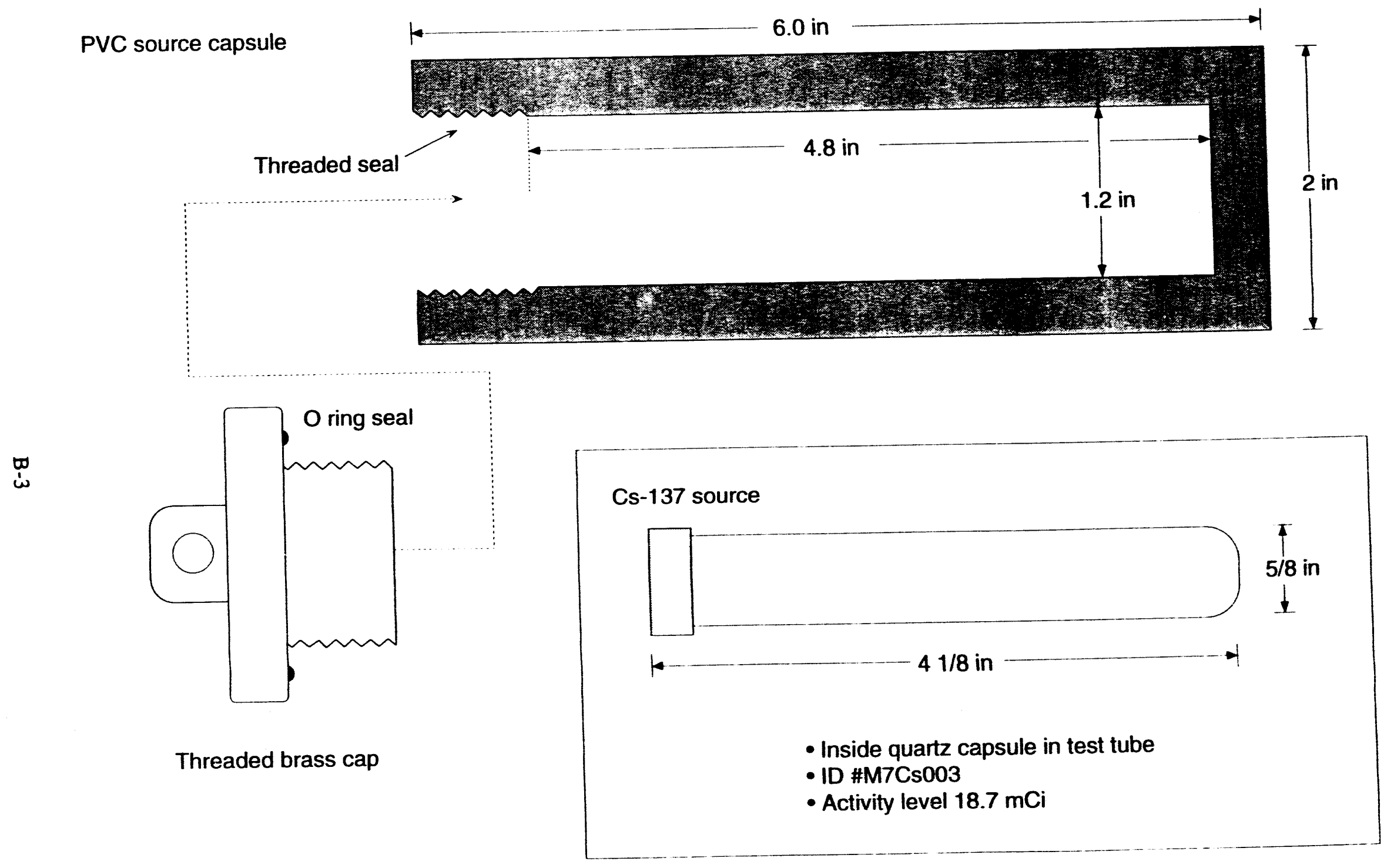

Figure B-1. Illustration showing dimensions of Cs-137 source and the PVC capsule that will be used for handling. For the dig-face characterization radiation tests, the PVC capsule is lowered into a buried access tube using a rope tied through the cap eyelet. 


\section{APPENDIX C}

\section{Detailed Test Procedures}

\section{C-1. Basic Experimental Procedure}

The dig-face characterization performance tests will consist of a series of experiments. Each experiment will involve setting up the manual trolley and collecting data from one or more sensors over known buried targets within the Characterization Cell of the INEL Cold Test Pit. The basic procedure is as follows:

1. Assume that all target materials have been placed and their locations recorded. For metal detection tests, target materials are those previously buried and recorded during construction of the Cold Test Pit additions. For fluid contaminant tests, isopropyl alcohol and dilute saline solutions will be placed in the ground through a tube at a known lucation and allowed to migrate. For radiation tests, a Cs-137 source will be encapsulated in a retrievable container and placed in the subsurface through a PVC access tube.

2. Set up the trolley over the test area, level, put data acquisition online, establish coordinate system and check positioning accuracy per Section 9.2, Item 5 .

3. Run trolley load tests, sensor tests, and data acquisition system tests.

4. Perform survey with desired sensors throughout the 2-ft head space above the ground surface. Station spacing and elevation spacing will be determined through preliminary testing and modified during data acquisition as necessary.

5. Remove a layer of soil and transport off dig face. The thickness of the layer will initially be 6 in, but can be modified at the discretion of project personnel. Soil will be removed manually. Any objects, fluids, soil irregularities, etc., discovered during excavation are noted according to position in a field notebook. Soil samples may be taken during fluid contamination experiments to establish concentration levels if necessary.

6. Perform survey over new surface.

7. Remove additional soil layer. 
8. Iterate Steps 5 and 6 until the area has been fully excavated.

9. Move trolley to next area and repeat Steps 2 through 9 until all desired tests have been completed.

\section{C-2. Detailed Procedure for Surveying a Test Area}

The trolley will track the sensor position using radial encoders. A set of presurveyed stakes will be placed within each new test area and marked with position and elevation coordinates. These stakes will serve to verify the accuracy in the trolley positioning system. Before beginning a new experiment, the trolley must be moved into position over each stake and the $x, y$, and $z$ offsets recorded. The trolley position should agree with the pre-surveyed position within \pm 1 inches in $x, y$, and $z$.

The survey then proceeds in a series of elevation steps, beginning with a survey of the airspace above the undisturbed ground. Sensors will first be profiled across the pit, making measurements every $\Delta x$. The trolley span will then be moved $\Delta y$ along the pit, followed by collection of a new $\Delta x$ profile. After the entire pit has been surveyed using one sensor head, a single profile will be repeated at random for quality control purposes. After surveying in this manner with all applicable sensors, the sensor height is lowered by $\Delta z$.

Once the airspace above the pit has been surveyed, soil removal will begin in 6 in. to 1 foot layers. Stakes will be marked with elevation lines to guide soil removal. After each step of soil removal, a new sensor elevation will be set and the survey will continue. When buried objects are encountered, their position will be measured off and recorded in field notebooks before removal.

Data will be displayed on a computer screen as it is collected. An engineer will monitor the incoming data to make certain that sensors are operating properly. The data will be stored initially in mass storage and backed up on tape at convenient intervals.

At the end of each day, the data will be transferred from mass storage into a data base. This data base will be designed to facilitate data access during data analysis. Data analysis will proceed according to direction from N. E. Josten and P. Graebner. Data analysis will begin as soon as adequate data have been accumulated and continue on a part time basis while field operations are ongoing. After field work is completed, data analysis will be pursued in eamest.

\section{C-2}


Once preliminary conclusions have been drawn regarding the project objectives, report writing will begin. 


\section{APPENDIX D \\ Proposed Specifications for Additional Test Cells}

Subject to time restrictions and avallability of suppon personnel, additional test cells will be constructed adjacent to the Characterization Cell of the INEL Cold Test Pit. Materials for the additional test cells have been collected and will be stored at the Cold Test Pil awaiting approval of cell construction. A schematic drawing of the proposed test cells is provided in Figure D-1.

In the event that the new cells are actually constructed, R. C. Callow, N. E. Josten, or L. G. Roybal will observe construction and obtain as-built measurements of the locations and dimensions of each test object. These measurements will be compiled onto a scaled drawing and delivered to BWID before commencement of any dig-face testing. 


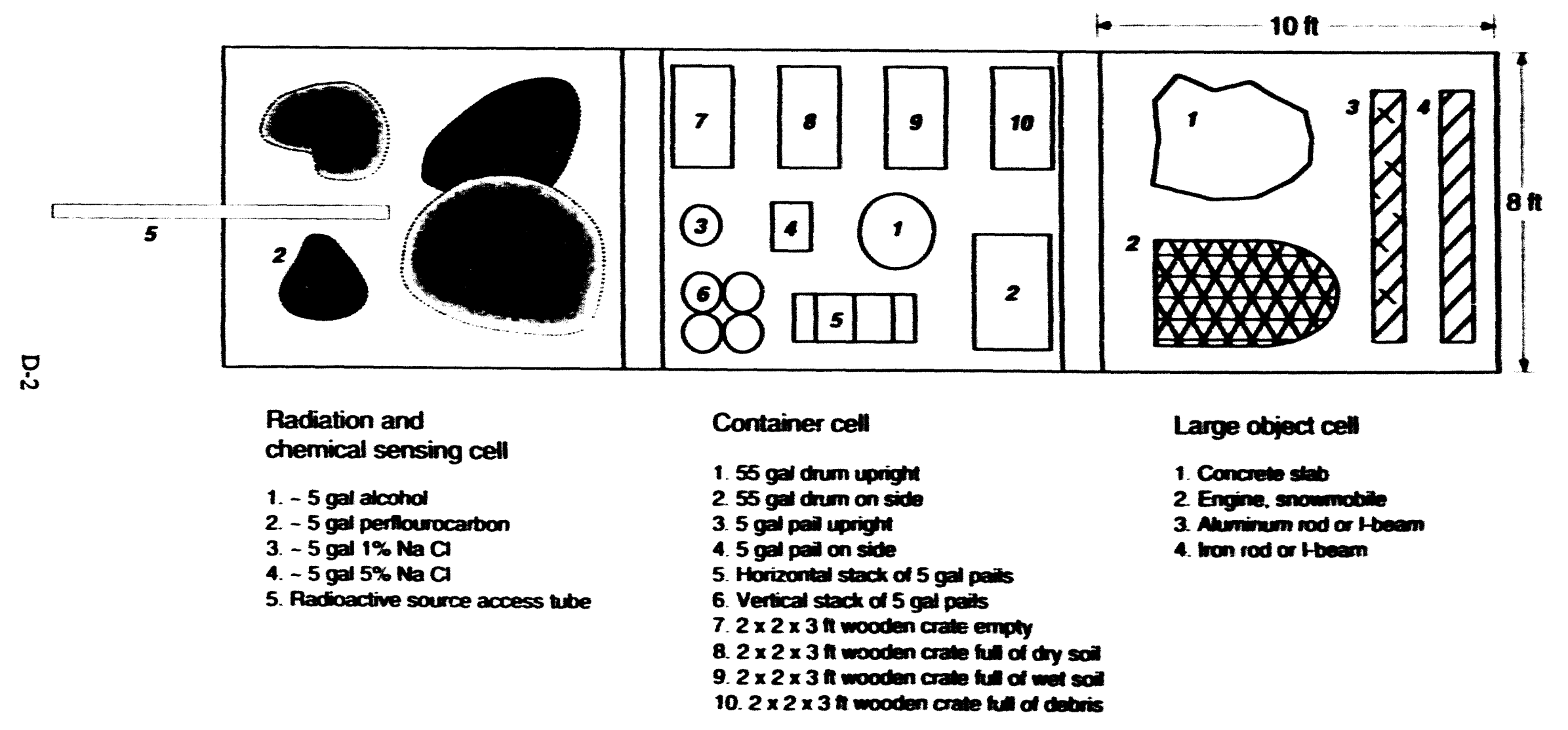

Figure D-1. Proposed layout for a shallow characterization test cell to be conseructed adjacent wo the current Characterization Cell at the Cold Test Pit. 


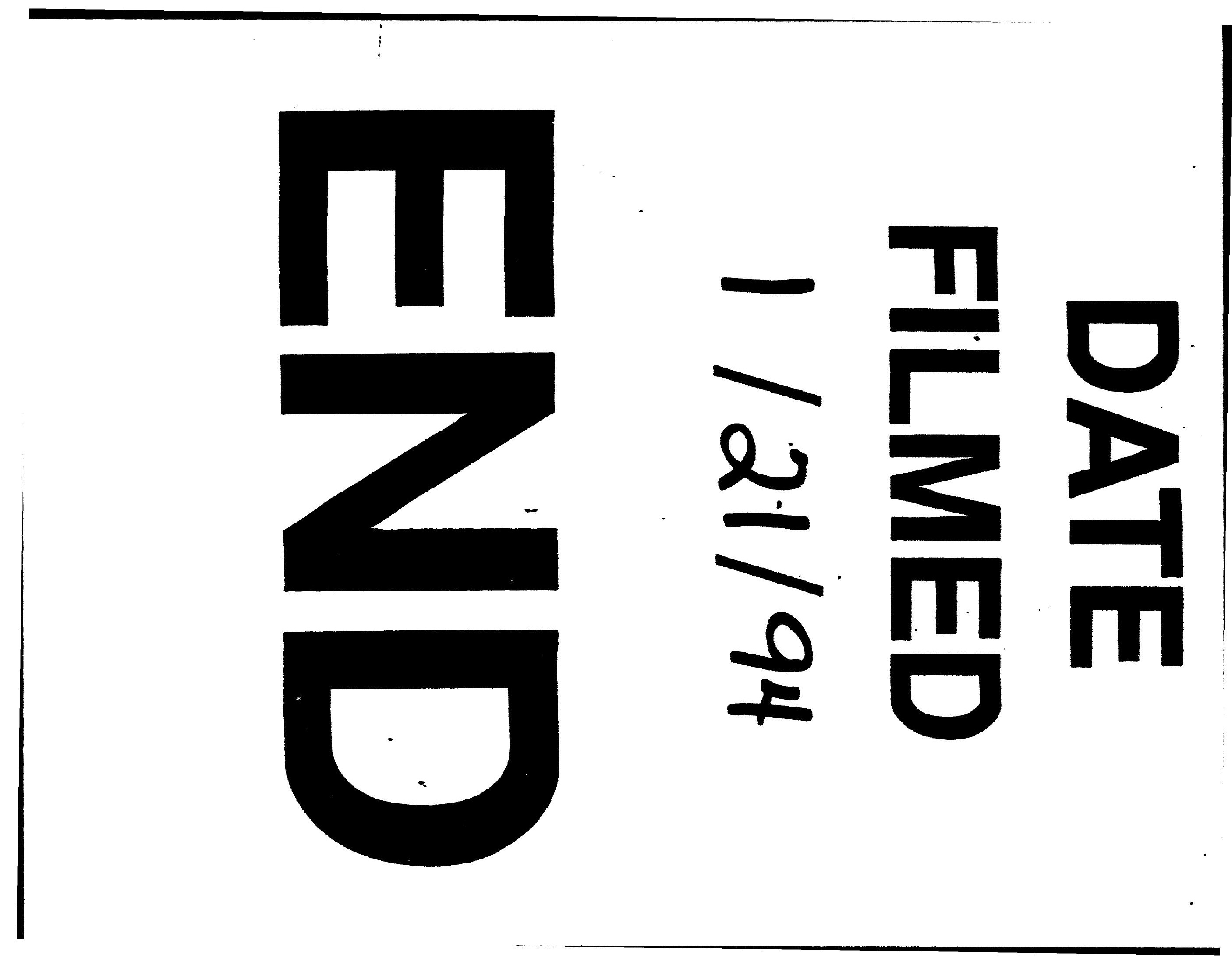



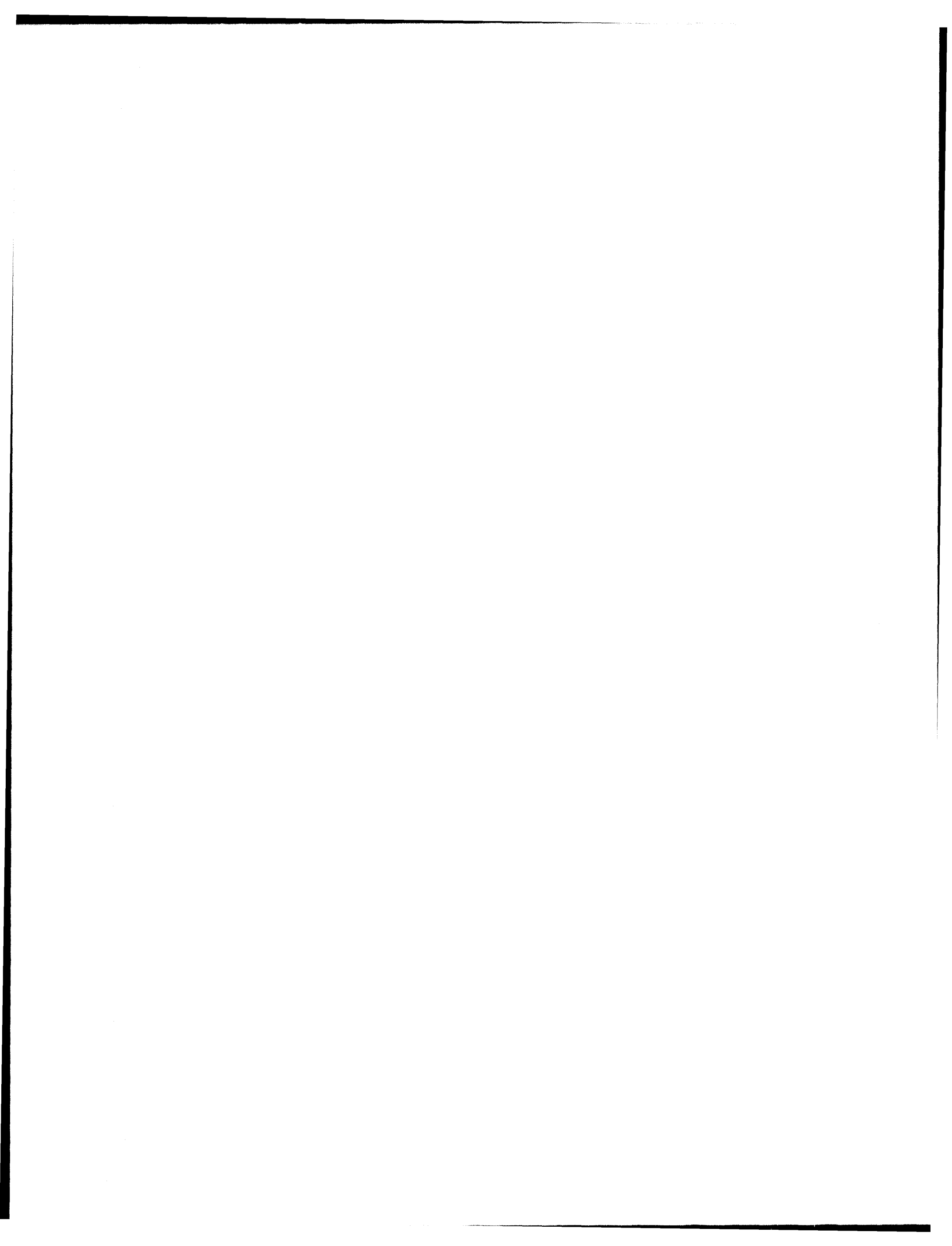